\title{
On the Orographically Generated Low-Level Easterly Jet and Severe Downslope Storms of March 2006 over the Tacheng Basin of Northwest China
}

\author{
GUANGXING ZHANG \\ Institute of Desert Meteorology, China Meteorological Administration, and \\ Institute of Central-Asian Weather, Urumqi, Xinjiang, China \\ DA-LIN ZHANG \\ State Key Laboratory of Severe Weather, Chinese Academy of Meteorological Sciences, Beijing, China, and \\ Department of Atmospheric and Oceanic Science, University of Maryland, College Park, College Park, Maryland \\ SHUFANG SUN \\ Urumqi Meteorological Bureau, Urumqi, Xinjiang, China
}

(Manuscript received 23 November 2017, in final form 26 March 2018)

\begin{abstract}
A high-latitude low-level easterly jet (LLEJ) and downslope winds, causing severe dust storms over the Tacheng basin of northwestern China in March 2006 when the dust source regions were previously covered by snow with frozen soil, are studied in order to understand the associated meteorological conditions and the impact of complex topography on the generation of the LLEJ. Observational analyses show the development of a large-scale, geostrophically balanced, easterly flow associated with a northeastern high pressure and a southeastern low pressure system, accompanied by a westward-moving cold front with an intense inversion layer near the altitudes of mountain ridges. A high-resolution model simulation shows the generation of an LLEJ of near-typhoon strength, which peaked at about $500 \mathrm{~m}$ above the ground, as well as downslope windstorms with marked wave breakings and subsidence warming in the leeside surface layer, as the largescale cold easterly flow moves through a constricting saddle pass and across a higher mountain ridge followed by a lower parallel ridge, respectively. The two different airstreams are merged to form an intense LLEJ of cold air, driven mostly by zonal pressure gradient force, and then the LLEJ moves along a zonally oriented mountain range to the north. Results indicate the importance of the lower ridge in enhancing the downslope winds associated with the higher ridge and the importance of the saddle pass in generating the LLEJ. We conclude that the intense downslope winds account for melting snow, warming and drying soils, and raising dust into the air that is then transported by the LLEJ, generated mostly through the saddle pass, into the far west of the basin.
\end{abstract}

\section{Introduction}

The Tacheng basin (TCB), located in the extreme northwest of China, is surrounded by complex topography: Mt. Bahatai to the north, Mt. Baerluke and Mt. Mayiler with parallel high ridges to the southeast, and Mt. Qiurkayer to the east, as well as several saddle passes/ gaps between mountains. One saddle pass with a ridge of 950-m altitude in a valley between the latter two mountains will be our major focus (see Figs. 1a,b). Although it is situated at $45^{\circ}-47^{\circ} \mathrm{N}$ in the midlatitude westerlies, the

\footnotetext{
Corresponding author: Guangxing Zhang, zhanggx@idm.cn
}

TCB often experiences east-to-southeasterly flows in the lower troposphere during the cold season. More intense east-to-southeasterly winds, termed herein as the lowlevel east-to-southeasterly jet (LLEJ), take place in the eastern portion of the TCB. This LLEJ appears to be closely related to intense downslope winds and funneled flows through the saddle pass upslope from the so-called "Laofengkou" (LFK; in Chinese, meaning "a wellknown intense wind mouth"). The downslope motion of the east-to-southeasterly winds, after passing the constricting saddle pass, could generate intense winds at LFK under favorable conditions, as its name implies. The downslope windstorms and LLEJ are responsible for the 


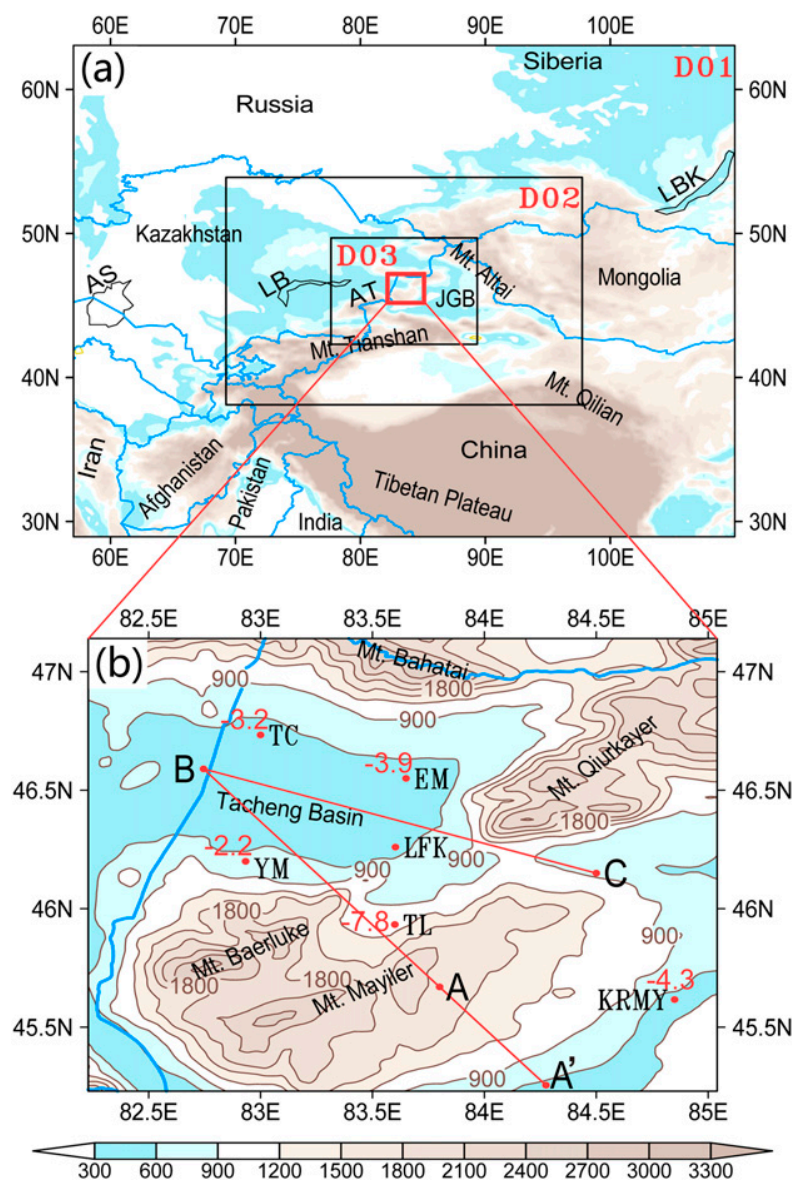

FIG. 1. Model domains and topography. (a) The triply nested domains with grid lengths of 27 (D01), 9 (D02), and $3 \mathrm{~km}$ (D03), terrain heights (shadings), and national borders (in blue), as well as major locations mentioned in text (LB denotes Lake Balhash, LBK Lake Baikal, AS Aral Sea, AT Mt. Alatau, and JGB Junggar basin). (b) Terrain contours (and shadings; $\mathrm{m}$ ) within the red rectangle in (a) at 300-m intervals. The red rectangle in (a) represents the influence area of the dust storm under study. Red dots in (b) denote the location of LFK $\left(46.2^{\circ} \mathrm{N}, 83.6^{\circ} \mathrm{E} ; 598 \mathrm{~m} \mathrm{MSL}\right)$, and available weather stations: TC $\left(46.7^{\circ} \mathrm{N}, 83^{\circ} \mathrm{E} ; 535 \mathrm{~m} \mathrm{ASL}\right), \mathrm{YM}$ $\left(46.2^{\circ} \mathrm{N}, 83^{\circ} \mathrm{E} ; 715 \mathrm{~m} \mathrm{MSL}\right)$, Emin $\left(\mathrm{EM}, 46.6^{\circ} \mathrm{N}, 83.7^{\circ} \mathrm{E} ; 522 \mathrm{~m}\right.$ MSL), TL $\left(45.9^{\circ} \mathrm{N}, 83.6^{\circ} \mathrm{E} ; 1078 \mathrm{~m} \mathrm{MSL}\right)$, and KRMY $\left(45.6^{\circ} \mathrm{N}\right.$, $84.9^{\circ} \mathrm{E} ; 450 \mathrm{~m} \mathrm{MSL}$ ) (similarly for the rest of the figures). Minimum surface temperatures at these stations during 11-12 Mar 2006 are also plotted. Lines $\mathrm{B}-\mathrm{C}, \mathrm{B}-\mathrm{A}$, and $\mathrm{B}-\mathrm{A}^{\prime}$ in (b) show the locations of vertical cross sections used in Figs. 7a,b, 7c,d, and 8a,b, respectively.

development of many severe dust storms over the TCB. In fact, little soil land could be seen at LFK and its vicinity as a result of the frequent sand/dust-driving winds.

One of the severe dust storms occurred on 12-13 March 2006, as given in Fig. 2, showing that a dust plume extended mainly from a location about 20-30 km upstream from Yumin (YM) and then northwestward over a distance of $800-1000 \mathrm{~km}$, with a width of $50-100 \mathrm{~km}$. Surface
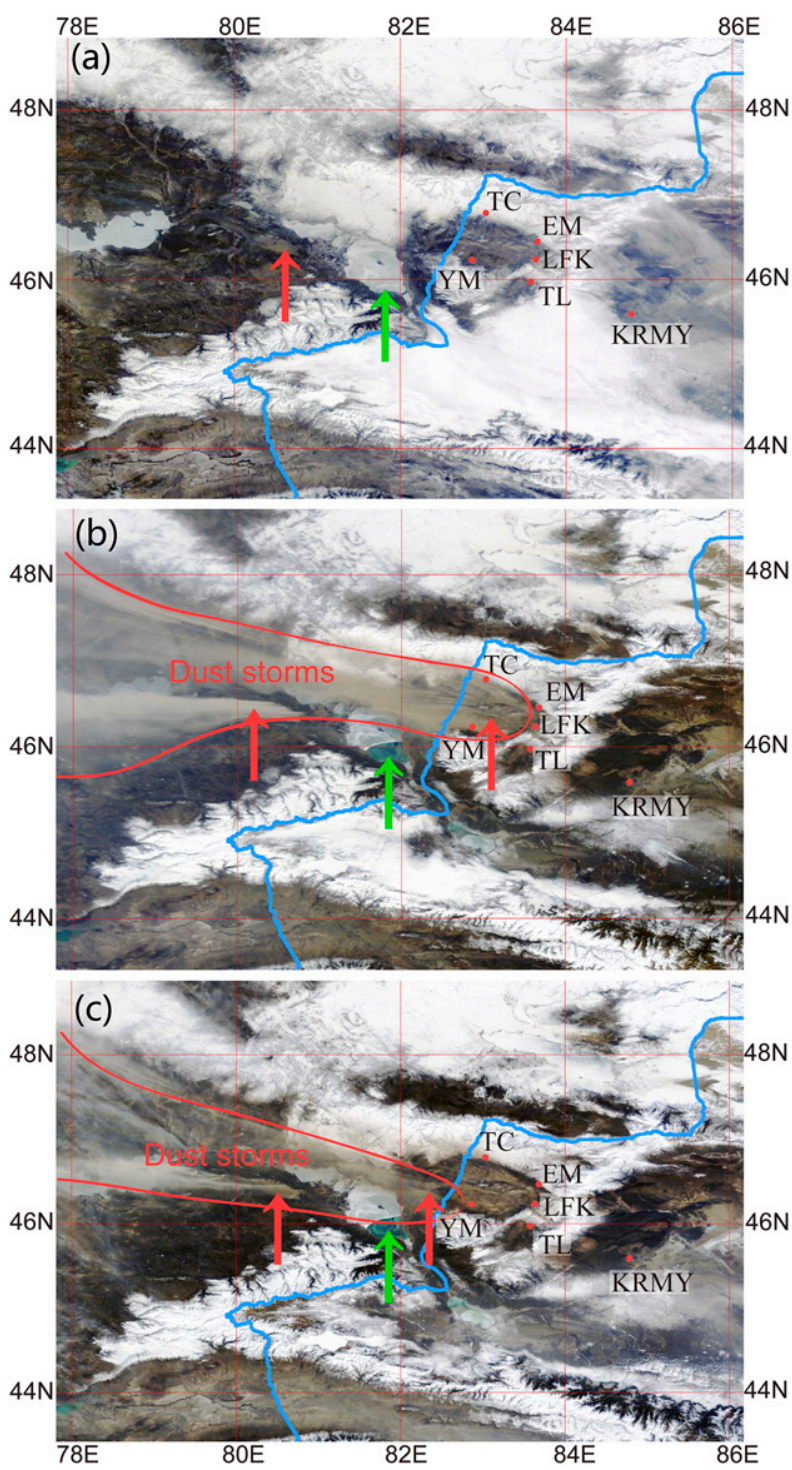

FIG. 2. The Terra/MODIS natural colored composite dust storm images obtained by combining data from three channels (i.e., 620 $672,545-565$, and $459-479 \mathrm{~nm}$ ) that are sensitive to sand and dust: (a) 1155 LST 11 Mar, (b) 1055 LST 12 Mar, and (c) 1138 LST 13 Mar 2006. White, dark gray, blue, and dusty gray colors represent snow cover, bare land, water, and dust, respectively. Red lines highlight the distribution of floating dust particles. Red dots denote available Chinese weather stations over the study area. Thick blue lines are national borders. A red arrow is used to denote the initiating location of a separate dust plume associated with a gap between Mt. Alatau and Mt. Baerluke that is discussed in section 5, and a green arrow is used to show the location of Lake Alakol.

stations at Tacheng (TC) and YM recorded the peak $(10 \mathrm{~m})$ surface wind speeds $\left(V_{\mathrm{SFC}}\right)$ of $24-26 \mathrm{~m} \mathrm{~s}^{-1}$, which were much greater than the typical threshold of surface dust-raising wind velocity of less than $10 \mathrm{~m} \mathrm{~s}^{-1}$ over a desert area (Zhu and Zhang 2010). This wind/dust storm caused considerable local structural damage and 
significant transportation and environmental problems. Of particular interest is that this dust plume originated from the source regions that were more-or-less covered by snow (see Fig. 2a), with frozen soil [as indicated by subfreezing surface $(2 \mathrm{~m})$ temperatures $\left(T_{\mathrm{SFC}}\right)$ in Fig. 1b] over the TCB in this cold month.

With the recent tourist and economic growth and environmental concerns in the region, there has been growing interest in the understanding and prediction of such extreme wind/dust storm events. However, few studies have been performed so far to study the dynamic impact of complex topography and favorable atmospheric conditions that are responsible for the development of such LLEJ-downslope wind-related dust storms, due partly to sparse population near the remote border with the country of Kazakhstan and partly to the lack of appropriate observations. Thus, we are motivated to fill this gap by studying the generation of the 1213 March 2006 LLEJ-downslope wind-related dust storm (hereafter, the 12-13 March wind/dust storm) through observational analyses and real-data numerical simulations.

Severe downslope windstorms have been well documented on the lee slopes of many mountain barriers around the world, such as the Chinook in the Rocky Mountains, foehn over the Alps, bora in the Dinaric Alps, and zonda in the Andes of Argentina. In particular, there have been vigorous studies on the development of severe downslope windstorms since the flight observational analysis of a severe downslope wind event by Lilly (1978). Several field campaigns have also been conducted during the past 20 years to study downslope windstorms, such as in the Alps (Bougeault et al. 2001), the Pyrenees (Bougeault et al. 1993), the Sierra Nevada (Grubišić et al. 2008), and Arizona's Meteor Crater (Lehner et al. 2016). Three major dynamical mechanisms have been widely discussed in the literature to explain the severe downslope windstorm phenomenon (see Smith 1985; Durran 1986, 1990; Lin 2007): (i) upward-propagating mountain waves are reflected downward at a mean-state critical (or wind reversal) level, leading to wave amplification (Klemp and Lilly 1978); (ii) wave breaking generates a self-induced critical level that reflects wave energy downward to cause resonant amplification (Clark and Peltier 1984); and (iii) hydraulic jump in a two-layer fluid, with either a stable layer below a less-stable layer (Durran 1986) or a neutral bottom layer and a stable upper layer separated by an inversion layer (Vosper 2004; Smith and Skyllingstad 2011; hereafter V04 and SS11, respectively). The third mechanism is an analogy to shallow water flowing over an obstacle as the flow transitions from subcritical (i.e., $F_{R}$ is much less than unity) upstream to supercritical (i.e., $F_{R}$ is greater than unity) at the mountain top. The Froude number, $F_{R}$, is defined as

$$
F_{R}=U / \sqrt{g^{\prime} H}
$$

where $U$ and $H$ are the mean wind speed normal to the obstacle in and the depth of the bottom layer, respectively; $g^{\prime}=g\left(\Delta \theta / \theta_{0}\right)$ is the reduced gravity; and $\theta_{0}$ and $\Delta \theta$ are the respective mean potential temperature in the bottom layer and vertical potential temperature difference across the inversion layer (see V04; SS11). Many studies appear to support the hydraulic analog that can be easily described in a one-layer shallow-water dynamical framework (Long 1954; Smith 1985; V04; SS11).

Previous studies suggest the following favorable conditions for the development of intense downslope windstorms: (i) long mountain ridges with a gentle windward slope but a steep lee slope (Smith 1977; Lilly and Klemp 1979); (ii) strong cross-mountain surface pressure gradients with high pressure upstream and low pressure downstream (Whiteman 2000); (iii) an inversion layer near the mountain ridge level (Brinkmann 1974; Mobbs et al. 2005) or a neutral planetary boundary layer (PBL) capped by an intense inversion (V04; SS11); (iv) a critical level or weak winds with a reversed wind direction in the midtroposphere (Clark and Peltier 1984); and (v) the absence of a cold air mass on the lee side prior (Durran 2003).

Gap flows or jets, including those through a saddle pass, have also been observed in many places, but mostly over coastal regions: for example, in the Columbia River Gorge (Cameron 1931; Sharp and Mass 2004), the Strait of Juan de Fuca (Reed 1931; Colle and Mass 2000), the Shelikof Strait of Alaska (Lackmann and Overland 1989), the Howe Sound of British Columbia (Jackson and Steyn 1994), the Chivela Pass of Mexico (Steenburgh et al. 1998), and the Vratnik Pass in the Dinaric Alps of Croatia (Belusic et al. 2013). These flows are typically a class of low-level flow of cold air and driven by pressure gradients across mountain barriers. Gap winds differ from downslope winds in that the latter are more related to large-amplitude, two-dimensional (2D) lee waves of relatively smaller scales downstream (Smith 1985). Although flows through a saddle pass are similar to pure gap winds, the former may be considered as the latter influenced by downslope motion, to a certain extent, due to the presence of a ridge in the valley. Saddle passes with various sloping steepness should appear more between high mountain ridges over interior continental regions.

While downslope winds and gap flows have been extensively studied for many mountainous regions around the world, little work has been pursued for the TCB region, especially when the barrier, saddle pass/gap, and 
parallel ridges (with variable slopes) effects of mountains are all operative. Thus, the objectives of this study are to (i) document the development of the 12-13 March wind/dust storm and the associated synoptic-scale conditions with available observations; (ii) study the $3 \mathrm{D}$ structures and evolution of the downslope windstorm and LLEJ using a 72-h model simulation with the finest grid length of $3 \mathrm{~km}$; and (iii) discuss the relative roles of the downslope windstorm and the LLEJ in the generation of the 12-13 March dust storm.

The next section provides a brief overview of the severe dust storm events observed at a few representative surface stations, followed by a synoptic analysis of the largescale environment in which the wind/dust storm evolved, using the National Centers for Environmental Prediction (NCEP) Final reanalysis with $1^{\circ} \times 1^{\circ}$ resolution. Section 3 describes the mesoscale model used for this study and necessary verification of the model simulation. The complex mountain morphology will also be described. Section 4 shows the model-simulated 3D structures and evolution, as well as the dynamics of the LLEJ and downslope winds leading to the development of the 12$13 \mathrm{March}$ wind/dust storm. Section 5 discusses the impact of melting and sublimating snow and surface warming associated with the downslope winds on the generation of the severe dust storm. The spatial variation of the LLEJ under the influences of local topography will also examined in terms of pressure gradients in the TCB.

\section{Observational analysis}

\section{a. Overview}

Despite lacking high-resolution observations near the remote border, for the present case, several surface weather stations over the eastern genesis region of the TCB, such as TC, YM, and Tuoli (TL), captured well the intense near-easterly winds. Meanwhile, one upper-air rawinsonde station on the windward side of the mountains [i.e., Karamay (KRMY)] could provide an excellent description of upstream conditions for the development of the LLEJ and downslope winds (see Figs. $1 \mathrm{~b}$ and 2 for their locations).

Figure 3 shows the time series of hourly (near easterly) $V_{\mathrm{SFC}}$ and $T_{\mathrm{SFC}}$ and the associated dusty weather recorded at two representative stations (i.e., TC and YM), as well as the observed $\mathrm{PM}_{10}$ concentration that was only available routinely at TC. The TC and YM stations were representative because they were influenced more by the saddlepass funneled flows or gap winds and the downslope windstorm, respectively, albeit near the northern and southern edges of the dust storm. (Unfortunately, no surface observing stations are set at LFK or the central portion of the dust storm.) Airborne sand and dust originated within roughly $20-50 \mathrm{~km}$ upstream (east) of the stations. Of note is that the respective southeasterly and easterly dust-raising $V_{\mathrm{SFC}}$ of more than $20 \mathrm{~m} \mathrm{~s}^{-1}$ began at $\mathrm{TC}$ and YM near 0900 LST (UTC + 6h) 11 March (Figs. 3a,c, and $3 e, f)$, whereas the earliest high concentrations of airborne dust and sand (high $\mathrm{PM}_{10}$ ) were reported at 0305 (0000) LST and 0646 LST 12 March, respectively, when the local subfreezing $T_{\mathrm{SFC}}$ at both stations was still dropping during the early morning hours (Figs. 3b,e). As will be discussed in section 5, the 6-9-h delay in onset of the dust storm after the strong $V_{\mathrm{SFC}}$ began, and the different delay time of more than $3.5 \mathrm{~h}$ between the two stations, could be attributed to the fact that the dust source regions were, to a variable extent, covered by snow with frozen underlying soils. The dust storm ended at TC at 1526 LST 13 March when its $V_{\mathrm{SFC}}$ dropped below $15 \mathrm{~m} \mathrm{~s}^{-1}$. Unlike the weakening of the southeasterly $V_{\mathrm{SFC}}$ at $\mathrm{TC}$ during the nighttime of 12 March, the easterly $V_{\mathrm{SFC}}$ at $\mathrm{YM}$ remained as strong as that throughout the dust storm period, indicating the possibility of two different mechanisms by which the intense $V_{\mathrm{SFC}}$ at the two stations were generated, as will be seen in section 4 .

Figures $3 \mathrm{~b}$ and $3 \mathrm{e}$ also show well the diurnal cycles of observed $T_{\mathrm{SFC}}$ at the two stations, with the warmest and coldest values of over $7.5^{\circ} \mathrm{C}$ and below $-2.5^{\circ} \mathrm{C}$ during the daytime and nighttime, respectively; the amplitude of the diurnal cycle at the ground surface should be much greater than that of $T_{\mathrm{SFC}}$. Note the different behaviors of the daytime peak $T_{\mathrm{SFC}}$ at both stations on 12 and 13 March in the presence of lofted sand and dust: that is, about $5^{\circ} \mathrm{C}$ less than, but similar in magnitude to, those on 11 March, respectively. As will be seen from the model simulation, these behaviors could not be attributed to attenuation of incoming solar radiation by airborne sand and dust. Of relevance to this study is that $T_{\mathrm{SFC}}$ at $\mathrm{YM}$ remained, on average, at about $2^{\circ} \mathrm{C}$ during the nighttime of 12 March, while TC kept its $T_{\mathrm{SFC}}$ under freezing values. The different scenarios in $T_{\mathrm{SFC}}$ also indicate different mechanisms generating the intense $V_{\mathrm{SFC}}$ (and $T_{\mathrm{SFC}}$ ) at the two stations, as will be discussed in section 4 .

\section{b. Synoptic background}

Figure 4 shows synoptic charts at 1200 LST 11, 12, and 13 March 2006, corresponding to the times just before the LLEJ/dust storm, the strongest stage of the storm, and near the ending time of the storm, respectively (cf. Figs. 4 and 3). The 1200 LST is used herein because the Terra/MODIS satellite usually travels across the TCB within an hour of this local noontime (Fig. 2).

The 500-hPa flows over Eurasia at 1200 LST 11 March 2006 were characterized by two troughs west and east side of an intense synoptic-scale ridge of warm anomalies (Fig. 4a). This ridge in the height field extended from 


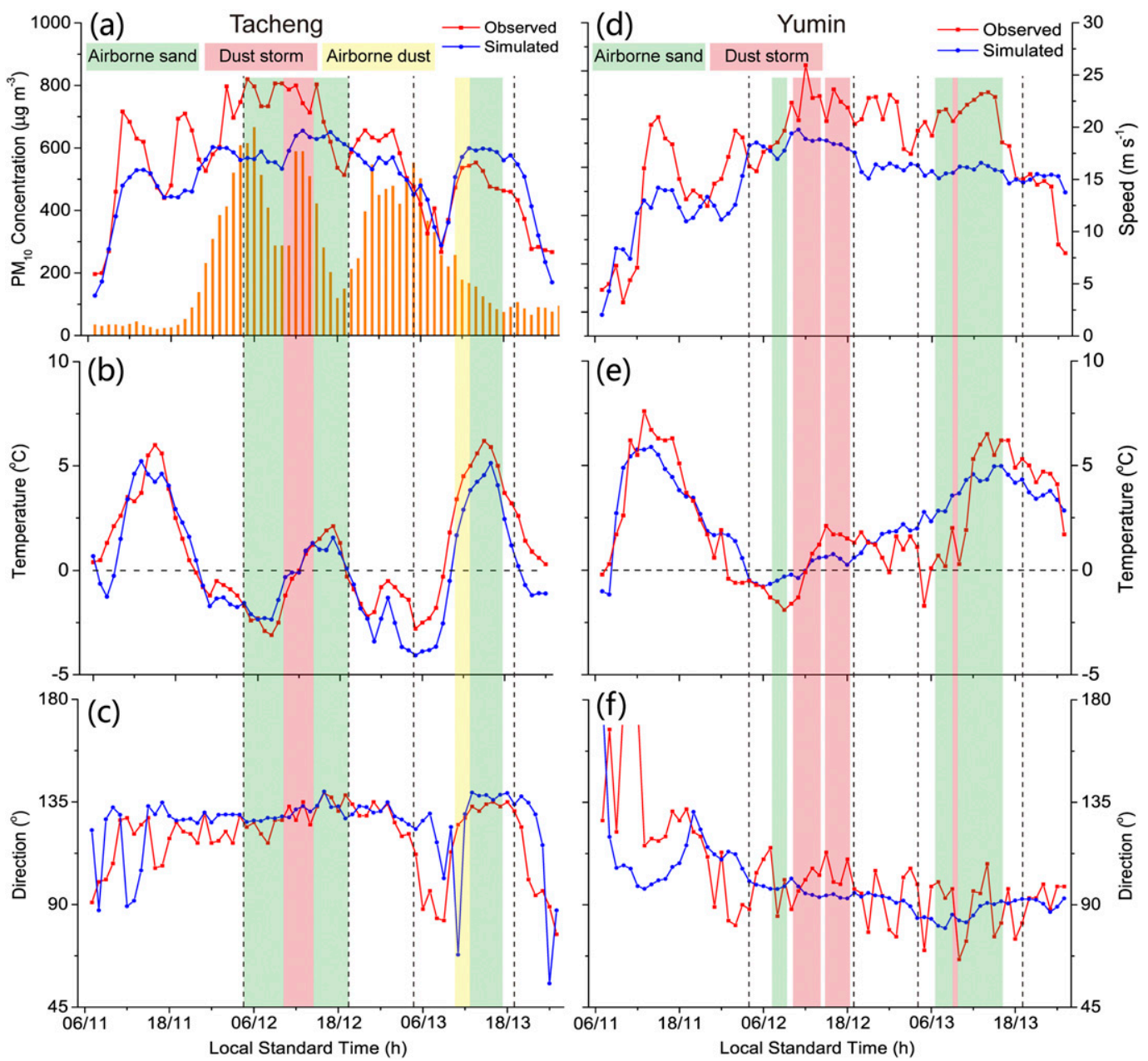

FIG. 3. Time series of the simulated (blue) and observed (red) surface fields: (a) wind speed ( $\mathrm{m} \mathrm{s}^{-1}$ ) at $z=10 \mathrm{~m}$; (b) temperature $\left({ }^{\circ} \mathrm{C}\right)$ at $z=2 \mathrm{~m}$; and (c) wind direction $\left({ }^{\circ}\right)$ at $z=10 \mathrm{~m}$, all at hourly intervals, superimposed with the periods of recorded airborne sand, dust storm, and airborne dust (shaded) at TC during the period of 0600 LST 11 Mar-0000 LST 14 Mar 2006. Vertical dashed lines denote the daytime period (i.e., 0400-1900 LST), while horizontal dashed lines in (b) and (e) denote the freezing $T_{\mathrm{SFC}}$ of $0^{\circ} \mathrm{C}$. (d)-(f) As in (a)-(c), but for YM. Since airborne sand/dust were not recorded during evening hours due to limited visibility, the $\mathrm{PM}_{10}$ concentration at TC is given as orange bars in (a) to show the evolution of the dust storm, which increased from a prestorm value of $50 \mu \mathrm{g} \mathrm{m}^{-3}$ to a peak value of $660 \mu \mathrm{g} \mathrm{m}^{-3}$ at the onset of airborne sand, only with a short period of $100 \mu \mathrm{g} \mathrm{m}^{-3}$ around 1800 LST 12 Mar coinciding with a rapid decrease in $V_{\mathrm{SFC}}$. It then remained high until 1530 LST 13 Mar, when it dropped to less than $100 \mu \mathrm{g} \mathrm{m}^{-3}$. No observations of $\mathrm{PM}_{10}$ concentration were available at YM.

the Iranian Plateau northward to Lake Balkhash, merging with the Siberian ridge to form a dominant meridional circulation. The corresponding sea level pressure field showed a quasi-stationary intense high located between Lake Baikal to the northeast and Mt. Altai to the southwest with the central pressure of more than $1056 \mathrm{hPa}$, and a major surface trough extending from the Caspian Sea to the Iranian Plateau with a secondary trough extending to the TCB's southwest (Fig. 4d). This low-level westward pressure gradient force helped drive easterly winds across the mountain barriers into the TCB, as will be seen in section 4 . In contrast to Siberian's cold ridge, the low-level southeasterly flows ahead of a cold front had brought relatively warmer air into the study area, facilitating the subsequent penetration of cold air mass into the TCB.

As the southwest-northeast-oriented ridge axis at $500 \mathrm{hPa}$ rotated clockwise during its eastward progression, we see the formation of a zonally oriented trough with a cold center of $-44^{\circ} \mathrm{C}$ near Mt. Altai (Fig. 4a). Meanwhile, the northeasterly cold flows north of the trough axis contributed to the southward movement of the surface cold front (Fig. 4d). As a result, the TCB was found in the southwest margin of the intense surface 


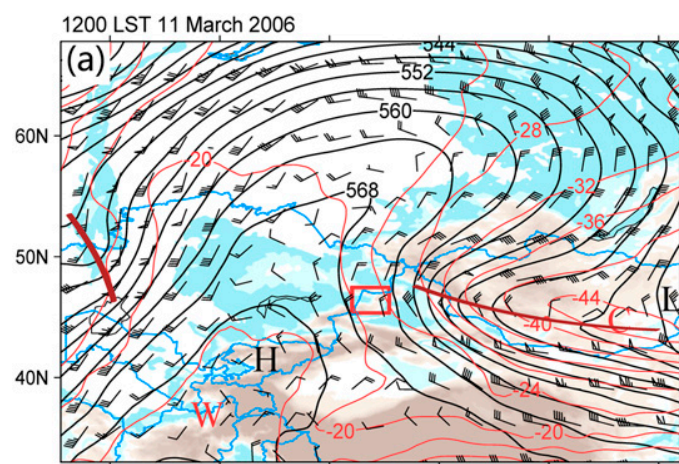

1200 LST 12 March 2006

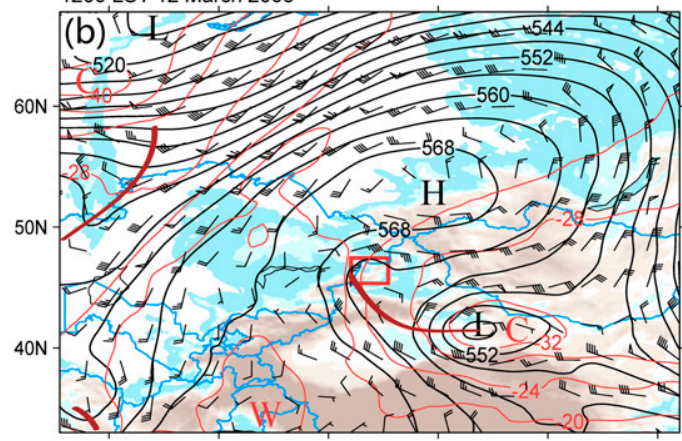

1200 LST 13 March 2006

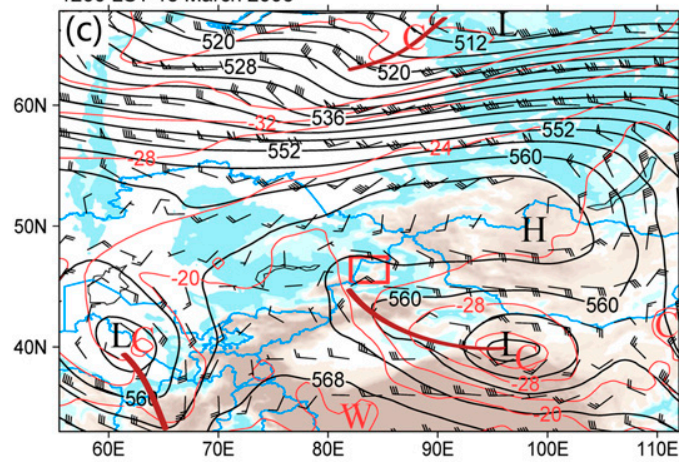

$\mathrm{H}$, Wind barbs and $\mathrm{T}$ at $500 \mathrm{hPa}$

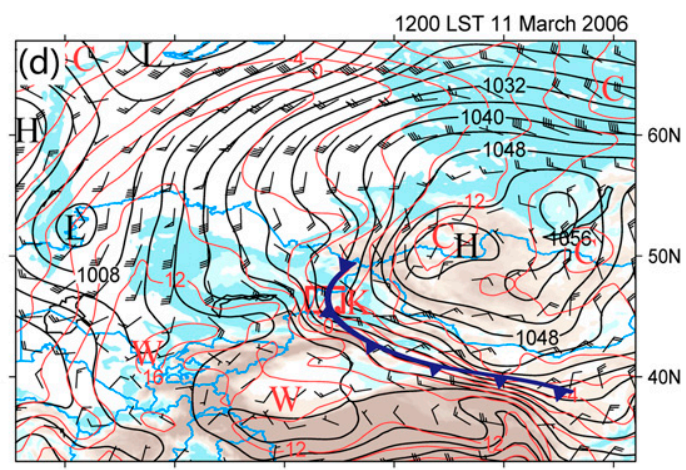

1200 LST 12 March 2006

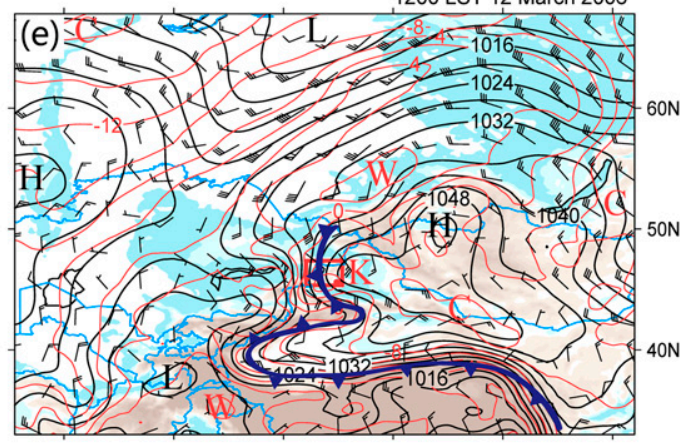

1200 LST 13 March 2006

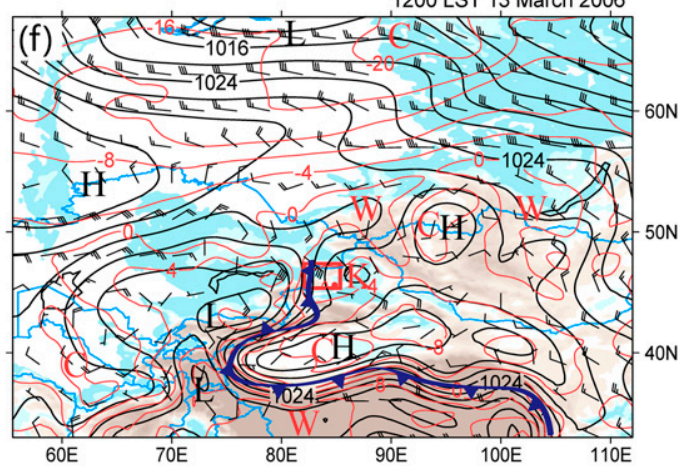

Psea, Wind barbs and $\mathrm{T}$ at $850 \mathrm{hPa}$

FIG. 4. (a)-(c): The NCEP's $1^{\circ} \times 1^{\circ}$ resolution reanalysis of geopotential heights (black) at 40-m intervals, temperature (orange) at $4^{\circ} \mathrm{C}$ intervals, and horizontal winds at $500 \mathrm{hPa}$. (d)-(f) The corresponding maps of sea level pressure (black) at 4-hPa intervals, temperature (orange) at $4^{\circ} \mathrm{C}$ intervals, and horizontal winds at $850 \mathrm{hPa}$, at (top) 1200 LST 11 Mar, (middle) 1200 LST 12 Mar, and (bottom) 1200 LST 13 Mar 2006. Each pennant, full barb, and half barb denotes a wind speed of 25,5 , and $2.5 \mathrm{~m} \mathrm{~s}^{-1}$, respectively. Terrain background is shaded in the same manner as that in Fig. 1a. A red rectangle is used to show the dust storm area under study. "H," "L," "W," and "C" denote the centers of high and low pressures and warm and cold air, respectively; "K" in (d)-(f) denotes the location of KRMY. Thick red lines denote trough axes, and thick blue lines denote national borders. The distribution of cold fronts is also shown.

high, within an easterly wind zone at $850 \mathrm{hPa}$. It was this easterly airflow that was associated with the formation of the LLEJ and downslope windstorms in the TCB.

By 1200 LST 12 March, the Siberian region was controlled by a nearly closed high aloft centered at $54^{\circ} \mathrm{N}$, $90^{\circ} \mathrm{E}$, as its original ridge moved significantly eastward, whereas the trough base moved slowly southwestward across the TCB to the northern slope of Mt. Tianshan (cf. Figs. 4b and 4a). Meanwhile, a closed low formed about $1000 \mathrm{~km}$ to the TCB's southeast. Our study area is now to the northwest of this low and the southwest of the high so that the resulting pressure gradient force supported the development of a deep layer of easterly winds with a wide meridional span. Thus, we may state that it was the pronounced meridional pressure gradients associated with the northeastern high and southeastern 


\section{(a) 0600 LST 11 March 2006}

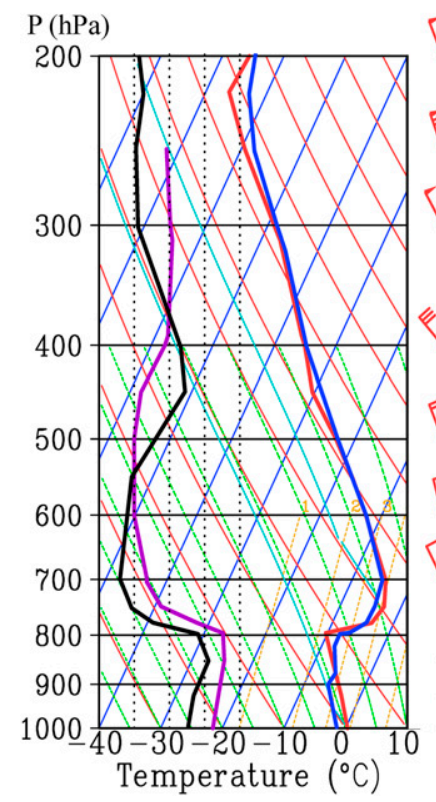

(b) 0600 LST 12 March 2006
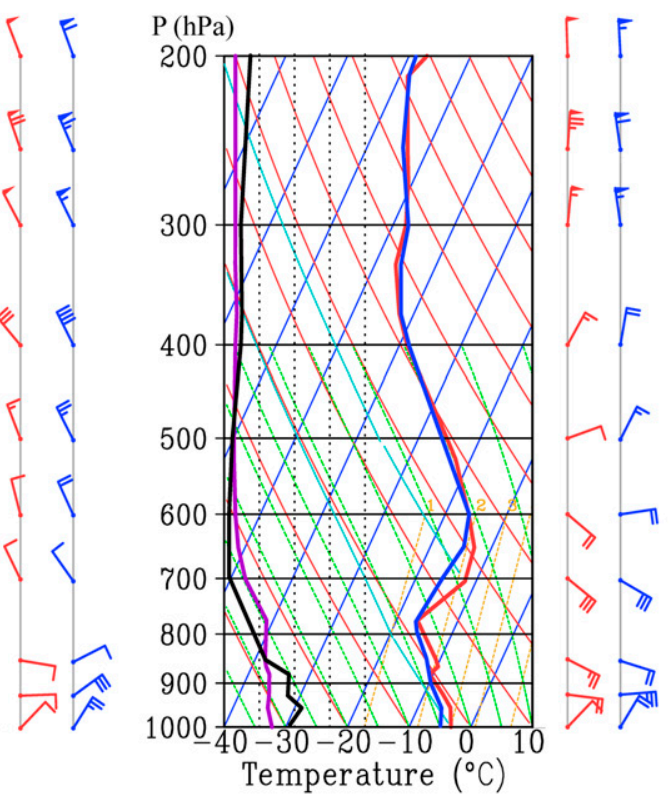

(c) 0600 LST 13 March 2006

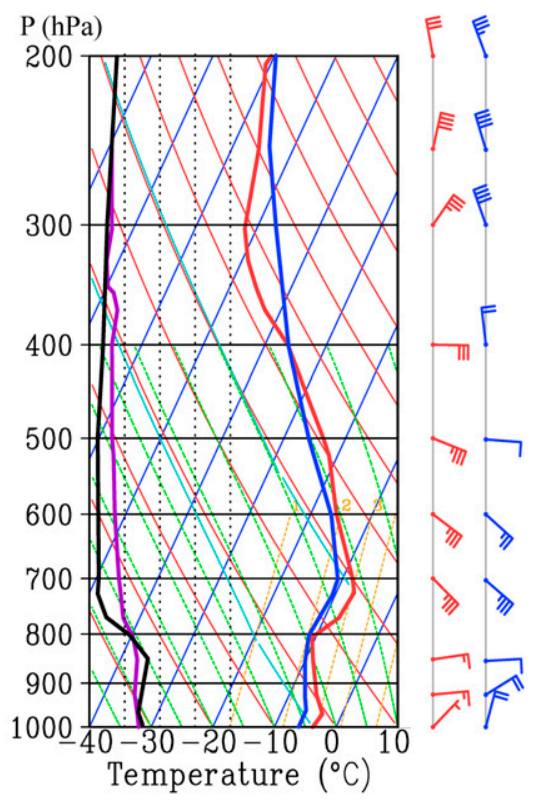

FIG. 5. Skew $T-\log p$ diagram (temperature and dewpoint temperature, ${ }^{\circ} \mathrm{C}$ ) observed (red) and simulated (blue) at KRMY (see Figs. $1 \mathrm{~b}$ and 2 for its location) at (a) 0600 LST 11 Mar, (b) 0600 LST 12 Mar, and (c) 0600 LST 13 Mar 2006. A full wind barb is 5 m s ${ }^{-1}$.

low systems that accounted geostrophically for the development of a deep layer of sustained easterly winds above the PBL into the study area. Moreover, the lowlevel easterly flow pushed the surface cold front westward, while the warm air of the Iranian Plateau origin formed a surface trough to the south (Fig. 4e), thereby increasing the low-level westward pressure gradient force for driving the easterly winds across the mountain barriers.

By 1200 LST 13 March, the northern ridge axis has rotated clockwise to a nearly zonal orientation from Lake Baikal to Lake Balkhash, while the zonally oriented trough and closed low previously over Mt. Tianshan have moved east-southeastward, to the east of Mt. Tianshan and the west of Mt. Qilian, respectively (Fig. 4c). Although the height patterns still helped maintain the geostrophically balanced easterly flow over the study area, its intensity became much weaker than before due to the weakening of meridional pressure gradients (cf. Figs. $4 \mathrm{~b}$ and $4 \mathrm{c}$ ). Similarly, the surface trough to the TCB's south retreated westward and weakened, diminishing the low-level zonal pressure gradients (Fig. 4f). All these indicate that the large-scale, lower-tropospheric easterly flow was weakening with time.

\section{c. Soundings at the windward sloping surface}

Although downslope windstorms are generated on the lee sides of high mountains, their timing and intensity are more or less determined by upstream dynamical and thermodynamic conditions. It is fortunate that an upperair station at KRMY, located on the upslope side of Mt. Mayiler, could provide necessary upstream soundings for the present study. Figure 5a shows clearly cold, east-tonortheasterly flows in the lowest 200-hPa near-neutral layer, with an intense inversion layer between 800 and $700 \mathrm{hPa}$ prior to the dust storm event, which is favorable for the development of downslope wind storms, according to V04. Subsequently, the inversion layer was lifted to $780-650 \mathrm{hPa}$, with a deep layer of cooling by east-tosoutheasterly flows up to $500 \mathrm{hPa}$ (Fig. 5b), as the lowlevel colder air mass was advected into the TCB following the westward-advancing surface cold front. The increased depth of easterly flows conformed to the southeastward displacement of the zonal trough axis at $500 \mathrm{hPa}$ across the TCB (cf. Figs. 5a,b and 4a,b), while the deep layer cold advection was consistent with the anticlockwise rotation of horizontal winds with height at KRMY. The directional change to northerly and northwesterly could provide a basic-state critical level (in the vertical cross section normal to the mountain ridge) where wave reflection might occur, giving rise to a severe downslope wind state. Meanwhile, a secondary inversion in the $900-880-\mathrm{hPa}$ layer emerged as the colder air mass continued to be advected across KRMY. This secondary inversion layer later deepened to $800 \mathrm{hPa}$ with greater static stability (cf. Figs. $5 \mathrm{c}$ and $5 \mathrm{~b}$ ). Note that $T_{\mathrm{SFC}}$ kept cooling from $0^{\circ}$ to $-4^{\circ} \mathrm{C}$ during the intensifying $V_{\mathrm{SFC}}$ period in the TCB. 
The presence of the inversion layer at an upstream site, albeit on a sloping surface, has important implications to the development of downslope windstorms, either funneled through the saddle pass or lifted over the parallel mountain ridges, since it tended to suppress topographical uplifting and strengthen its blocking effects (Lin 2007; SS11). If the flow could be lifted to the ridges, on the other hand, it may transition from subcritical to supercritical, as will be shown in section 4 , leading to the generation of a downslope windstorm (V04). Colman and Dierking (1992) and V04 indicated that an intense inversion near the mountain top is a necessary condition for the development of downslope windstorms. In addition, with the presence of an inversion layer, a self-induced critical level to reflect wave energy downward for wave amplification will not be required (V04; Gohm et al. 2008; SS11). Nevertheless, we are still uncertain about how the incoming flow could transition from subcritical to supercritical. How did the upstream conditions determine the generation and intensity of the LLEJ and downslope winds over the TCB? What are the roles of the saddle pass and the parallel mountain ridges in generating the intense LLEJ? Moreover, what were their 3D structures and evolution? What causes the different magnitudes and temporal changes of $T_{\mathrm{SFC}}$ and different directions in $V_{\mathrm{SFC}}$ between TC and YM? To answer all the above questions, we need to invoke high-resolution numerical model simulations, as presented in the next three sections.

\section{Model description and verification}

\section{a. Model description and mountain morphology}

In this study, a one-way, triply nested grid, version 3.3.1 of the Weather Research and Forecasting (WRF) Model (Skamarock et al. 2008), is used to examine the development of the March 2006 LLEJ and downslope winds and the associated dust storm. The three model domains have $(x, y)$ dimensions of $217 \times 139$ (D1), $307 \times 193$ (D2), and $445 \times 271(\mathrm{D} 3)$, with grid lengths of 27,9 , and $3 \mathrm{~km}$, respectively (Fig. 1a). D3, centered at $46.0^{\circ} \mathrm{N}, 83.0^{\circ} \mathrm{E}$, covers an $(x, y)$ area of $1332 \mathrm{~km} \times 810 \mathrm{~km}$. There are 50 layers in the vertical, with 13 layers below $850 \mathrm{hPa}$ and 24 layers below $500 \mathrm{hPa}$. The model top is set at $50 \mathrm{hPa}$.

The model physics schemes used include (i) the singlemoment 6-class (WSM6) cloud microphysical scheme (Hong and Lim 2006); (ii) the Rapid Radiative Transfer Model (RRTM) (Mlawer et al. 1997) for longwave radiation and the Dudhia (1989) shortwave radiation scheme; (iii) the Yonsei University PBL scheme (Hong et al. 2006); (iv) the slab scheme with five soil layers (Zhang and Anthes 1982; Skamarock et al. 2008); and (v) the Kain (2004) cumulus parameterization scheme for D1 and D2. The Kain scheme is bypassed in D3. However, little rainfall is generated in the present case because of very dry conditions (see Fig. 5). Note that herein, we attempt to simulate the development of the LLEJ and downslope winds, rather than the related dust storm. To simulate the latter, one has to use a comprehensive land surface model in which snow and ice coverage/depth, soil moisture, and latent heat release, as well as a dust-driving parameterization together with a dust-transport scheme, are incorporated (e.g., Liu et al. 2007).

The model is initialized at 0000 LST 11 March with the NCEP's $1^{\circ} \times 1^{\circ}$ Final reanalysis and integrated for $72 \mathrm{~h}$, ending at 0000 LST 14 March 2006. The NCEP's reanalysis at 6-h intervals is also used to specify the outermost lateral boundary conditions. The model terrain is obtained from 30-s-resolution data. Figure $1 \mathrm{~b}$ shows that Mt. Baerluke and Mt. Mayiler both sit on a high plateau of $1200 \mathrm{~m}$ with their southwest-northeast-oriented parallel ridges, but they are nearly perpendicular to the incoming east-to-southeasterly flows. In addition, both mountains consist of two separate ridges longitudinally with their high peaks located to the southwest. A gentle windward slope and variable lee slopes (i.e., from gentle to steep), with parallel ridges between them and more elevated terrain to the southwest, plus an east-westoriented constricting saddle pass and the intersection of Mt. Bahatai and Mt. Qiurkayer at an angle smaller than $45^{\circ}$, provide a complex orographic morphology for studying the development of the downslope winds and LLEJ over the TCB.

\section{b. Model verification}

Because of the limited observations, we only verify the model simulation against surface reports at two stations, TC and YM, and upper-air soundings at KRMY. It is apparent from Figs. 3a and 3c and Figs. 3d and $3 \mathrm{f}$ that the model reproduces the onset and ending times, and the amplitudes and directions of the intense $V_{\mathrm{SFC}}$ at TC and YM, except during some periods when the simulated $V_{\mathrm{SFC}}$ are up to $10 \mathrm{~m} \mathrm{~s}^{-1}$ weaker than the observed. Note that the simulated surface fields at YM are taken at a location that is about $6 \mathrm{~km}$ to the north of its observatory site. This is done because YM in the simulation is located within a meso- $\beta$-scale lee cyclone with an easterly (southerly) flow to the north (south). As can be seen from Fig. 6f, the simulated southeasterly $V_{\mathrm{SFC}}$ at about $10 \mathrm{~km}$ to the north of YM reaches 23-25 m s${ }^{-1}$, which is similar to the observed $V_{\mathrm{SFC}}$ shown in Fig. $3 \mathrm{~d}$; similarly, the simulated $V_{\mathrm{SFC}}$ at $\mathrm{TC}$ would be comparable to the observed if the verification site were located at a point about $3-5 \mathrm{~km}$ to the south. 

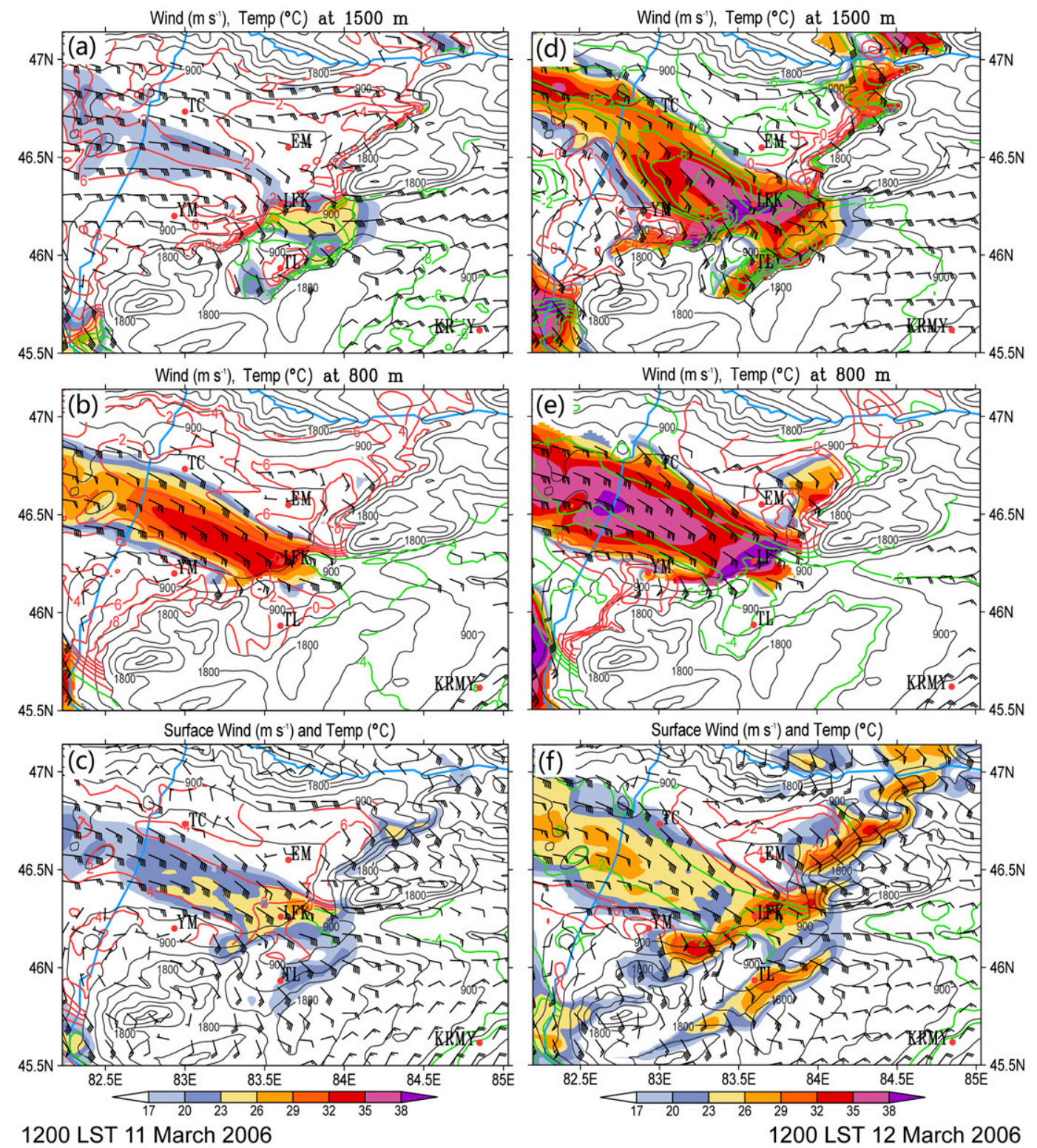

1200 LST 11 March 2006

FIG. 6. The simulated horizontal winds, superimposed with terrain heights (in gray), and temperature (green and red contours at intervals of $2^{\circ} \mathrm{C}$ for below and above $0^{\circ} \mathrm{C}$, respectively) at (a) 1500 and (b) $800 \mathrm{~m}$ MSL (winds underneath the ground are not plotted). (c) The surface (i.e., $z=10 \mathrm{~m}$ ) at 1200 LST 11 Mar 2006. (d)-(f) As in (a)-(c), but for 1200 LST 12 Mar 2006. Each pennant, full barb, and half barb denotes a wind speed of 25, 5, and $2.5 \mathrm{~m} \mathrm{~s}^{-1}$, respectively, with the wind speed greater than $17 \mathrm{~m} \mathrm{~s}^{-1}$ shaded. Thick blue lines denote national border.

In addition, the model reproduces quite well the diurnal cycles of $T_{\mathrm{SFC}}$ at both stations, including the daytime peak and nighttime subfreezing $T_{\mathrm{SFC}}$ on 11 March, the smaller daytime peak $T_{\mathrm{SFC}}$, and especially the different scenarios in $T_{\mathrm{SFC}}$ between TC and YM during the nighttime of 12 March. The results confirm our earlier conjecture that the different magnitudes and evolution of $T_{\mathrm{SFC}}$ are not attributable to the radiative effects of airborne sand/dust since the associated processes are not included in the present model configuration. Nevertheless, like the simulated $V_{\mathrm{SFC}}$, some errors are also present in $T_{\mathrm{SFC}}$ at both stations. They could be attributed partly to the narrower width of the simulated LLEJ or to less cold air masses transported into the TCB, and partly to the locations of TC and YM at the respective northern and southern edges of the LLEJ, as can be seen from Figs. $6 \mathrm{c}$ and $6 f$. Of our major concerns are the simulated above- or below-freezing $T_{\mathrm{SFC}}$ at the two stations, as well as the simulated intense dust-raising downslope winds, which will be discussed in the next two sections. 
The model also reproduces reasonably well the upstream soundings at KRMY (Figs. 5a-c). In particular, the continued low-level cooling; changes in the elevated inversion layer depth from $800-700 \mathrm{hPa}$ on 11 March to $780-600 \mathrm{hPa}$ on $12 \mathrm{March}$, and then $800-700 \mathrm{hPa}$ on $13 \mathrm{March}$; the lowest near-neutral layer; horizontal wind intensity; and vertical wind shear (as well as dry atmospheric columns) on the windward side, which determine the intensity and timing in the occurrences of the downslope windstorm, are all reasonably well simulated, especially the near-neutral PBL capped by an intense inversion and dry vertical columns.

\section{On the generation of the LLEJ and downslope windstorm}

Given the general agreements between the simulation and (limited) observations, we may diagnose the model output to answer the questions raised at the end of section 2. Here, we focus more on two stages of the storm development: 1200 LST 11 March, when the severe windstorm began to intensify but with little airborne dust generated, and 1200 LST 12 March, when the wind/dust storm entered the mature stage (Figs. 2, 3).

\section{a. Horizontal flow structures in the lower troposphere}

Figure 6 shows the horizontal flow structures at the surface, core level [i.e., $800 \mathrm{~m}$ above mean sea level (MSL)], and top portion (i.e., $1500 \mathrm{~m} \mathrm{MSL}$ ) of the LLEJ. First, we see from Figs. $6 \mathrm{c}$ and $6 \mathrm{f}$ the general blocking effects of the large mountain mass on the incoming easterly flow (associated with the pronounced zonal sea level pressure gradients shown in Figs. 4d,e) at both times, as indicated by diffluent $V_{\mathrm{SFC}}$, with more northeasterly flows to the south and more southeasterly flows to the north; the diffluent $V_{\mathrm{SFC}}$ is much less obvious at the mature stage. However, the incoming flows on early 11 March only appear in the lowest layers below $750 \mathrm{hPa}$, so they can only pass over the northeastern slopes of Mt. Mayiler and Mt. Baerluke, roughly below $1500 \mathrm{~m} \mathrm{MSL}$, or have to blow around their higher mountain barriers (cf. Figs. 5a and 6c).

Of major interest at the early stage of the LLEJ development is that (i) the incoming low-level diffluent flows, moving upslope and around the mountain ridges, undergo confluence and acceleration while being channeled between Mt. Qiurkayer and the parallel ridges, especially through the constricting saddle pass, and then descend the lee slope to generate stronger $V_{\mathrm{SFC}}$ at the lee foot; (ii) the consequent airstream, having the local $V_{\mathrm{SFC}}$ of greater than $26 \mathrm{~m} \mathrm{~s}^{-1}$ at LFK, is channeled to southeasterly; (iii) it is merged with the moderate easterly downslope winds on its south to form a diffluent east-to-southeasterly (e.g., between YM and TC) $V_{\mathrm{SFC}}$ airstream of more than $20 \mathrm{~m} \mathrm{~s}^{-1}$, with the peak wind speed of over $32 \mathrm{~m} \mathrm{~s}^{-1}$ at $800 \mathrm{~m}$ MSL (Figs. 6a-c); and (iv) this airstream is subsequently forced to blow parallel to the longitudinal axis of Mt. Bahatai; this will be better seen in section 5. Because of the northward sloping of Mt. Bahatai, this diffluent LLEJ increases in width at $1500 \mathrm{~m}$ MSL as it extends several hundreds of kilometers northwestward (Figs. 6a-c and 2b). These diffluent plus vertical structures reflect the $3 \mathrm{D}$ aspect of the channeled flows, in contrast to the small-scale downstream influences of downslope winds.

As the midlevel trough moves over the TCB, the incoming easterly flow strengthens and extends to $500 \mathrm{hPa}$ and higher by 1200 LST 12 March (Figs. 4b and $5 b$ ). As a result, a deep layer of intense easterly flows passes over the lower ridge of Mt. Mayiler, producing pronounced downslope winds in an elongated zone at its lee foot; a similar process occurs at the lee foot of Mt. Baerluke (Fig. 6f). The confluent (constricting) incoming flows and the diffluent (widening) outgoing LLEJ, as described in the preceding paragraph, become more evident (cf. Figs. 6c and 6f). The model-simulated peak $V_{\mathrm{SFC}}$ near YM and EM and at LFK reaches neartyphoon strength of $29-32 \mathrm{~m} \mathrm{~s}^{-1}$, with the wind/dust storm reaching its peak intensity stage (Figs. 2b, 3, and 6f). Note the generation of such local intense $V_{\mathrm{SFC}}$ at LFK after the incoming $V_{\mathrm{SFC}}$ of $6-8 \mathrm{~m} \mathrm{~s}^{-1}$ goes through the saddle pass, suggesting the collective funneling and orographic enhancing effects.

While the intense $V_{\mathrm{SFC}}$ near YM and EM could account for a large portion of airborne dust over the TCB (cf. Figs. 6f and 2b), these downslope $V_{\mathrm{SFC}}$ decrease to less than $23-26 \mathrm{~m} \mathrm{~s}^{-1}$ away from the foot of the lee slopes and merge into the intense LLEJ funneled through the saddle pass. Although pronounced downslope winds also occur on the southwestern lee side of Mt. Baerluke, they contribute little to the intense LLEJ in the subdomain but to another intense LLEJ to the south, as will be discussed in section 5 . Of significance is that the intense LLEJ at the surface can be sustained for many hours in terms of intensity and width, and its intensity even increases downstream (e.g., to more than $26 \mathrm{~m} \mathrm{~s}^{-1}$ ) (Fig. 6f), suggesting the occurrence of downward momentum transfer, which can be clearly seen from Figs. 7a and 7b, showing the distribution of large vertical turbulent momentum transfer coefficient $\left(K_{m}\right)$ below the LLEJ core level. As will also be shown in section 5, the fluctuating $V_{\mathrm{SFC}}$ along the LLEJ could be attributed to the changes in pressure gradients associated with local topography. In particular, the 800-m map shows the presence of an intense LLEJ core of over $35-38 \mathrm{~m} \mathrm{~s}^{-1}$, with a width of $50 \mathrm{~km}$ but sharp lateral 

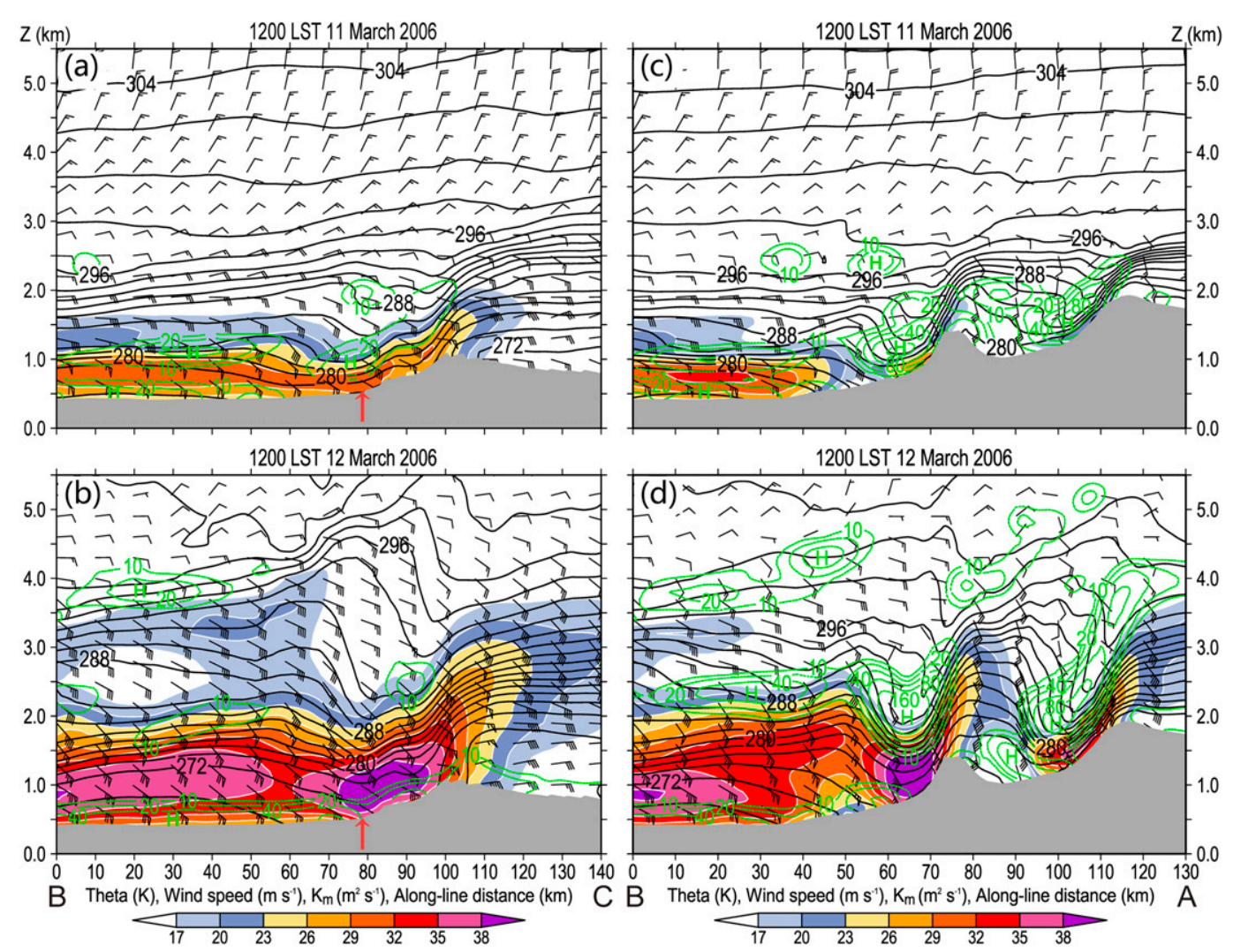

FIG. 7. Northwest-southeast vertical cross section of the simulated potential temperature $\theta$ (black contoured at intervals of $2 \mathrm{~K}$ ), horizontal winds (each pennant, full barb, and half barb denotes a wind speed of 25,5 , and $2.5 \mathrm{~m} \mathrm{~s}^{-1}$, respectively, with the wind speed greater than $17 \mathrm{~m} \mathrm{~s}^{-1}$ shaded), and vertical turbulent momentum transfer coefficient $K_{m}$ (green contoured at 10,20,40,80, and $160 \mathrm{~m}^{2} \mathrm{~s}^{-1}$ ) that is based on the Richardson numberdependent formulation of Hong et al. (2006), which is taken along line B-C given in Fig. 1b, valid at (a) 1200 LST 11 Mar and (b) 1200 LST 12 Mar 2006. The location of LFK is indicated by a red arrow. (c),(d) As in (a),(b), but for line B-A. Terrain is shaded in gray.

shears on both sides, which is enhanced from an incoming easterly flow of $10-15 \mathrm{~m} \mathrm{~s}^{-1}$ (cf. Figs. $5 \mathrm{~b}$ and $6 \mathrm{e}$ ). The LLEJ at $1500 \mathrm{~m}$ MSL is limited in its lateral dimension after impinging on Mt. Bahatai but is forced to flow parallel to the longitudinal axis of the mountain barrier starting from China's national border (Fig. 6d), where an elongated zone of stronger winds appears.

Now, it is necessary to discuss further the different behaviors of $T_{\mathrm{SFC}}$ on 11 and 12 March, as well as at TC versus $\mathrm{YM}$, as mentioned in sections $2 \mathrm{a}$ and $3 \mathrm{~b}$. Note first that $T_{\mathrm{SFC}}$ in the incoming flows are below $0^{\circ} \mathrm{C}$ at noontime of 11 and 12 March. Of relevance is that $T_{\mathrm{SFC}}$, as well as temperatures at 800 and $1500 \mathrm{~m}$ MSL in the LLEJ region, are all above $0^{\circ} \mathrm{C}$ on 11 March (Figs. 6a-c) but all below $0^{\circ} \mathrm{C}$ on 12 March, with a cold "pocket" at both 800 and $1500 \mathrm{~m}$ ASL (Figs. 6c-f). The presence of this cold pocket indicates that the LLEJ is mostly generated by the incoming easterly flows funneled through the saddle pass. Clearly, solar heating must account for the warming of the PBL and the warmest $T_{\mathrm{SFC}}$ over the
TCB on 11-13 March. However, this warming could not offset the advection of a deeper layer of inflowing colder air on 12 March (cf. Figs. 5b and 6d-f), which is responsible for the presence of much colder peak $T_{\mathrm{SFC}}$ than that on 11 March (Figs. 3b,e). On the other hand, we may assume that recovering to normal peak $T_{\mathrm{SFC}}$ on 13 March results from the weakening of the inflowing cold air mass, as discussed earlier. In contrast to the cold pocket in the LLEJ, we see the development of a warm pocket coinciding with a meso- $\beta$-scale lee cyclone near YM and EM (Fig. 6f), which is clearly associated with subsidence warming of downslope winds, as shown in Fig. 7. Unlike YM, TC is located near the tail of EM's warm pocket, thus receiving little influences of the downslope windstorm on $T_{\mathrm{SFC}}$ and $V_{\mathrm{SFC}}$, especially during the nighttime of 12 March (cf. Figs. 3a-c and $3 \mathrm{~d}-\mathrm{f}$ ). As will be discussed in section 5, it is the surface warming that accounts for the melting of the frozen land, facilitating the subsequent generation of airborne dust/ sand over the source region. 
After the passage of the midlevel trough, the TCB is situated in the zonally distributed ridge with weaker easterly flows. The simulated $850-\mathrm{hPa}$ incoming flows at KRMY decrease from about $10 \mathrm{~m} \mathrm{~s}^{-1}$ at 0600 LST 12 March to $5 \mathrm{~m} \mathrm{~s}^{-1}$ at 0600 LST 13 March, with increasing $T_{850}$ (Figs. 5b,c). This leads to the near-proportional weakening of the funneled and downslope winds, as well as the dust generation, east-to-southeasterly flows, and dust storm intensity over the TCB. The simulated maximum downslope wind $\left(V_{\mathrm{SFC}}\right)$ at the dust source region, corresponding to the termination of dust generation at 1600 LST 13 March, drops to $14 \mathrm{~m} \mathrm{~s}^{-1}$ (not shown).

\section{b. Vertical flow structures}

Figures $7 \mathrm{a}$ and $7 \mathrm{c}$ show vertical cross sections of the simulated flow field, valid at 1200 LST 11 March, that are taken through the saddle pass along line $\mathrm{B}-\mathrm{C}$ and are nearly normal to the parallel ridges along line $\mathrm{B}-\mathrm{A}$ (given in Fig. 1b), respectively. We see continuous acceleration of horizontal winds along the constricting saddle pass to about $23-26 \mathrm{~m} \mathrm{~s}^{-1}$ before descending a steep slope at LFK, leading to the generation of an LLEJ with the peak amplitude of 29-32 $\mathrm{m} \mathrm{s}^{-1}$ at about $800 \mathrm{~m}$ MSL or $500 \mathrm{~m}$ above ground level (AGL) (Fig. 7a). In contrast, uplifting to point A (1740 m MSL; Fig. 7c) before reaching the major ridge crest increases substantially the intensity of the inversion layer below $3 \mathrm{~km}$ MSL but decreases the normal to ridge inflow strength, as compared to both at KRMY (450 m MSL; Fig. 5a) and point C (830 m MSL; Fig. 7a). However, the bottom-layer flow begins to accelerate on the immediate downslope side (Fig. 7c).

Despite the presence of some three dimensionality, it is more meaningful to examine $2 \mathrm{D}$ flows in a two-layer hydraulic model with an interfacial inversion between $\theta=296$ and $282 \mathrm{~K}$ (i.e., with $\Delta \theta=14 \mathrm{~K}$ ), following V04 and SS11, as mentioned in section 1. For this purpose, Fig. $8 \mathrm{a}$ is plotted in the same way as Fig. 7c, except that its horizontal range is extended to the southeastern foothill with a normal flow component with respect to the parallel ridges. Negative vertical shear and a stagnation layer are evident near $\theta=296 \mathrm{~K}$ (or $700 \mathrm{hPa}$ ), so this layer could serve as a basic-state critical level to reflect any upward-propagating gravity wave. It is evident from Table 1 that $F_{R}$ increases from 0.34 at the upstream foothill to near unity (i.e., 0.97) at the major ridge ("R") due to a decrease in $H$ (i.e., from 1590 to $320 \mathrm{~m}$ ) and an increase in $U$ (i.e., from 9.6 to $12.1 \mathrm{~m} \mathrm{~s}^{-1}$ ), causing the flow transition from subcritical to supercritical. As a result, intense flows occur in the lowest sloping layers on the lee side as the thickness of descending isentropes (i.e., $\theta>286 \mathrm{~K}$ ) decreases
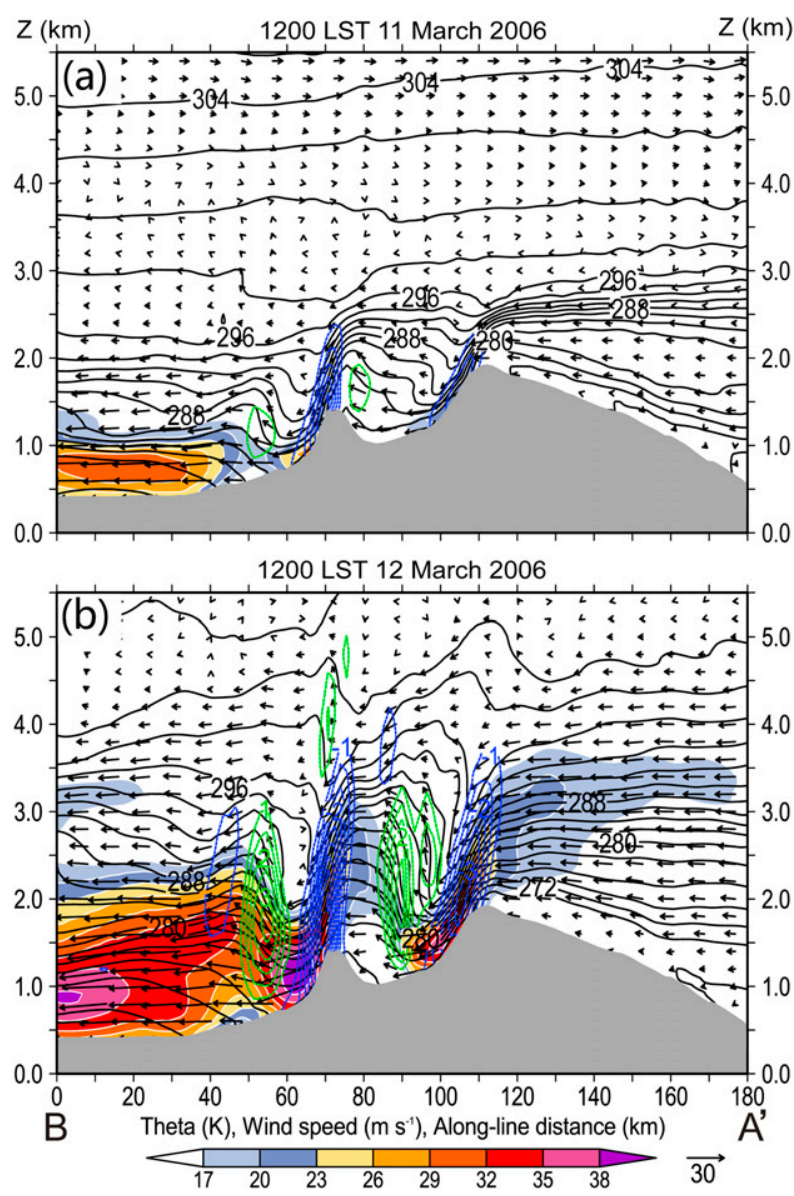

FIG. 8. (a),(b) As in Figs. 7c and 7d, respectively, but for (i) extending its horizontal axis southeastward from point $\mathrm{A}$ to $\mathrm{A}^{\prime}$ (see Fig. 1b) and (ii) superimposing in-plane flow vectors, in which vertical motion has been multiplied by 10 (upward/green, downward/blue, starting from $\pm 0.5 \mathrm{~m} \mathrm{~s}^{-1}$ without the null contour, at intervals of $0.5 \mathrm{~m} \mathrm{~s}^{-1}$ ). The major ridge (" $\mathrm{R}$ ") is located $110 \mathrm{~km}$ from point $\mathrm{B}$.

substantially from that on the windward side (Fig. 8a). Meanwhile, a lee trough in isentropes increases in amplitude along the lee downslope, with a stagnation zone in a shallow buoyantly unstable layer between 1.5 and $2.0 \mathrm{~km}$ MSL (i.e., a breaking wave), followed by an incipient hydraulic jump.

Note that unlike those shown in V04 and SS11, the inversion layer herein does not return to its original altitude after passing the major ridge due to significant lateral flow influences, which could be seen from the presence of large southerly winds on its lee side (see Fig. 7b). This 3D nature prevents us from quantifying the generation of another downslope wind event associated with the lower parallel ridge using the two-layer model through $F_{R}$. In fact, a peak wind of $26 \mathrm{~m} \mathrm{~s}^{-1}$ with a downdraft of more than $3 \mathrm{~m} \mathrm{~s}^{-1}$ develops at the lower 
TABLE 1. The magnitudes of dynamical variables in calculating the Froude number, $F_{R}=U / \sqrt{g^{\prime} H}$, and $g^{\prime}=g\left(\Delta \theta / \theta_{0}\right)$, where $U$ and $H$ are the mean wind speed normal to the parallel ridges and the height of the inversion layer, respectively; and the inversion intensity $\Delta \theta=\theta_{T}-\theta_{B}$, where $\theta_{T}$ and $\theta_{B}$ are the respective $\theta$ values at the top and bottom level of the inversion layer, at point $\mathrm{A}^{\prime}$ and the major ridge (R) at 1200 LST 11 Mar and 1200 LST 12 Mar 2006 along the vertical cross sections B-A' in Figs. 8a and 8b, respectively.

\begin{tabular}{lcccc}
\hline \hline & \multicolumn{2}{c}{1200 LST 11 Mar } & \multicolumn{2}{c}{1200 LST 12 Mar } \\
\cline { 2 - 5 } & Point A & Point R & Point A $^{\prime}$ & 9.7 \\
Point R \\
\hline$U\left(\mathrm{~m} \mathrm{~s}^{-1}\right)$ & 9.6 & 12.1 & 920 & 18.9 \\
$H(\mathrm{~m})$ & 1590 & 320 & $26=296-270$ & 265 \\
$\Delta \theta(\mathrm{K})=\theta_{T}-\theta_{B}$ & $14=296-282$ & 14 & 269 & 26 \\
$\theta_{0}(\mathrm{~K})$ & 277 & 277 & 0.34 & 1.18 \\
$F_{R}$ & 0.34 & 0.96 & & \\
\hline
\end{tabular}

ridge's lee side; both are much stronger than those associated with the major ridge. This result is consistent with that obtained from idealized simulations by Jiang and Doyle (2004), who showed enhanced downslope winds and wave breaking when a smaller-scale lower ridge (or ridges) is superimposed on a larger-scale gentle terrain slope. The LLEJ of more than $32 \mathrm{~m} \mathrm{~s}^{-1}$ farther northwest is more related to the saddle pass (cf. Figs. 6b, $7 \mathrm{a}, \mathrm{b}$, and 8a), since the downslope winds decrease significantly downstream (Smith 1985). Note also that most of the LLEJ takes place in the lowest 500-m layer of lower static stability than that of a shallow inversion layer above (i.e., $\theta=284-278 \mathrm{~K}$ at point B in Figs. 7a,c), which differs in depth and structure from the inversion in the incoming flows (cf. Figs. 7a,c and 5). We may assume that this capped inversion results from the intense shear-induced vertical mixing, as indicated by pronounced values of $K_{m}$ and reduced static stability below the LLEJ.

As the incoming horizontal flows at KRMY increase in amplitude (e.g., from 5 to $12 \mathrm{~m} \mathrm{~s}^{-1}$ at $850 \mathrm{hPa}$ ) and depth (i.e., from 200 to $500 \mathrm{hPa}$ ), as well as in coldness (from $0^{\circ}$ to $-5^{\circ} \mathrm{C}$ in $T_{\mathrm{SFC}}$ ), during the past $24 \mathrm{~h}$ (cf. Figs. 5a,b), so are the intensity and depth of the LLEJ over the TCB, especially the depth of easterly gale (i.e., greater than $17 \mathrm{~m} \mathrm{~s}^{-1}$ ) winds (Figs. $7 \mathrm{~b}, \mathrm{~d}$ ). The maximum horizontal winds at the feet of the saddle pass and parallel ridges reach over $38 \mathrm{~ms}^{-1}$, with the LLEJ attaining a similar peak intensity at more than $50 \mathrm{~km}$ downstream. The local LLEJ core far away from the mountain feet is caused by an increase in the pressure gradient force (Fig. 9b), as will be discussed in section 5 . Assuming that air parcels follow closely isentropic surfaces in the absence of intense vertical mixing, the saddle pass and the downslope winds appear to account for the LLEJ roughly at the core level (near $\theta=272 \mathrm{~K}$ ) and top portion $(\theta=276 \mathrm{~K})$, respectively, which also reflect their different altitudes of air masses entering the TCB. Note that the general easterly flows over the TCB are a class of cold stable air (seen as a subfreezing "cold pocket" in Figs. 6d-f) from upstream that decreases in depth westward. The westward-decreasing depths of the cold pocket are well represented by the downward-tilted $\theta=296$ and $300 \mathrm{~K}$ surfaces at 1200 LST 11 and 12 March, respectively, as the upstream inversion layer increases in depth (cf. Figs. 7 and 5). The low-level coldness is also consistent with the observed colder $T_{\mathrm{SFC}}$ during the dust

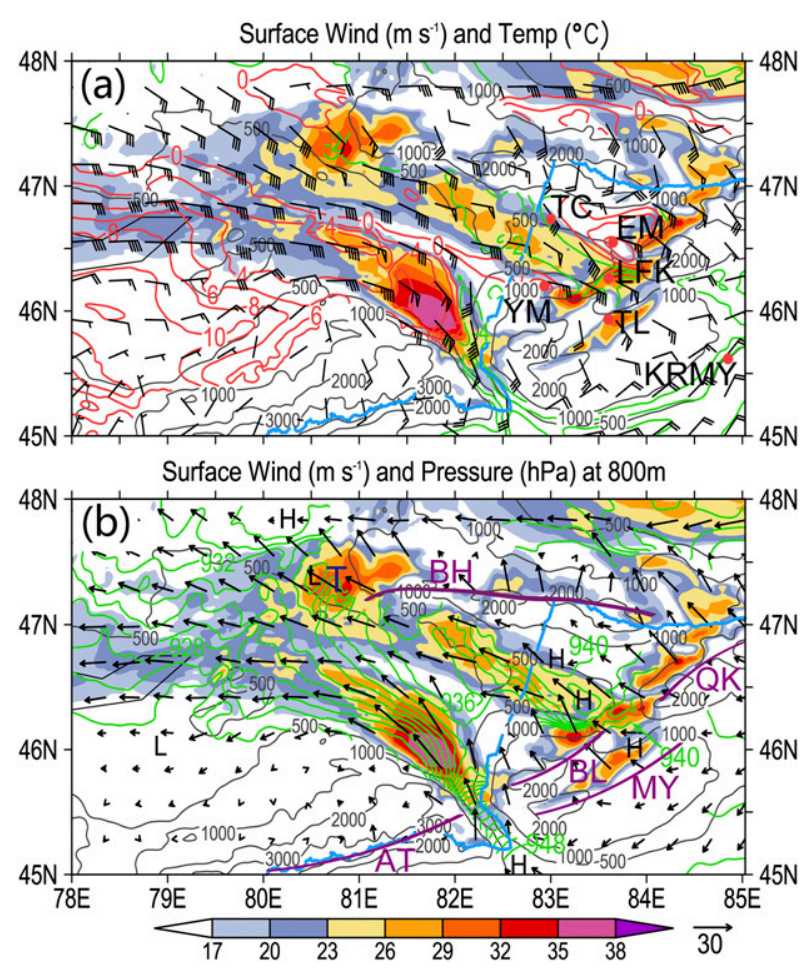

FIG. 9. (a) As in Fig. 6f, but over a larger domain to include the development of two LLEJs, and only terrain contours of 500, 1000, 2000 , and $3000 \mathrm{~m}$ are plotted. (b) As in (a), but for horizontal flow vectors and isobars (green contoured at $1-\mathrm{hPa}$ intervals) at $800 \mathrm{~m}$ MSL. Purple lines denote the mountain ridges of Bahatai (BH), Qiurkayer (QK), Baerluke (BL), and Alatau (AT); "H" and "L" indicate the local maximum and minimum pressure at $800 \mathrm{~m}$ MSL, respectively; and " $T$ " denotes the local maximum of the LLEJ at the exit of $\mathrm{BH}$. 
storm period, rather than with that on days with no dust storm (Figs. 3b,e).

The abovementioned increased low-level coldness thickens the inversion layer, whose depth is better represented by the thickness between $\theta=296$ and $270 \mathrm{~K}$ (i.e., $\Delta \theta=26 \mathrm{~K}$ ), with a near-neutral layer below (Fig. 8b). Mainly because of the increased $\Delta \theta, F_{R}$ at point $\mathrm{A}^{\prime}$ remains similar to that $24 \mathrm{~h}$ earlier (Table 1 ). However, we see more clearly how the incoming $U$ accelerates more rapidly than before when passing the major ridge (i.e., following better the two-layer hydraulic model of V04 and SS11). That is, the incoming air parcels undergo a transition from subcritical (i.e., $F_{R}=0.34$ and $U=9.7 \mathrm{~m} \mathrm{~s}^{-1}$ ) at point $\mathrm{A}^{\prime}$ to supercritical (i.e., $F_{R}=1.18$ and $U=18.9 \mathrm{~m} \mathrm{~s}^{-1}$ ) at the ridge, producing a breaking wave near $3.5 \mathrm{~km}$ MSL that amplifies in amplitude downslope (Fig. 8b). Another hydraulic jump, but with a shorter wave breaking, occurs as the downslope flow descends the lee slope of the lower ridge, giving rise to more intense downslope winds ( $U=$ $38.8 \mathrm{~m} \mathrm{~s}^{-1}$ ) with stronger vertical motion than those occurring $24 \mathrm{~h}$ earlier, again supporting the finding of Jiang and Doyle (2004).

In contrast, significant steepening of isentropic surfaces with increased wind speeds occurs in the lowest 0.5-1.0-km layer after passing the saddle pass (e.g., at LFK), but showing little evidence of wave breaking (Figs. 7a,b) and surface warming (Figs. 6c,f). This steepening can be attributed mostly to the rapid lateral spreading of cold air mass at the exit of the saddle pass plus the subsequent downslope motion. The downslope enhancement should be much smaller than that associated with the parallel ridges due to the presence of a gentle lee slope and a well-mixed bottom layer of about 1-km depth within the saddle pass (Fig. 7b); the latter is consistent with the finding of SS11, who showed that an elevated inversion layer tends to prevent the generation of an intense downslope windstorm. Apparently, the 2D hydraulic theory cannot be applied to flows through the saddle pass because of the rapid widening of its lateral terrain at the exit. As will be discussed in the next section, the flow intensity through the saddle pass is determined mainly by the pressure gradient force across the barrier, like a gap flow, and then enhanced gravitationally by the downslope motion. The resulting flows could not generate the dust storm over the frozen land, despite its typhoon strength, because of the lacking surface warming.

\section{On the development of the severe dust storm and the spatial variation of the LLEJ}

After examining the development of the downslope winds and LLEJ, it is logical to explore how the associated dust storm was generated and why it could extend far to the west. Figures $1 \mathrm{~b}$ and $2 \mathrm{a}$ show snow coverage over high-elevated mountainous regions, such as KRMY, and the vicinities of TL, TC, EM, and LFK prior to the dust storm. However, the snow coverage is absent on most of the windward slopes, near TL, and over the LFK-TC-YM triangle, where most airborne dust originated (cf. Figs. 2c and 2a). Clearly, snow must completely disappear and soil moisture must be mostly evaporated prior to the operation of the intense sand/ dust-raising $V_{\mathrm{SFC}}$. We could not attribute the diminished snow to surface warming through solar heating, but likely to the intense, warm and dry downslope winds or Chinooks, as shown in Fig. 6f. We may speculate that the presence of strong surface winds facilitates both the sublimation of snow and blowing snow that might account partly for the reduction of snow coverage on the windward slopes, and more importantly, that it is mainly the melting of snow cover by the Chinooks that was responsible for the absence of snow and then the drying of soil at the leeward foot. Of course, further modeling studies with sophisticated land surface schemes may be performed to validate the above hypothesis.

Note another narrow zone of a stronger dust plume that was generated with little influences from downslope winds to the south of the dust storm under our study, as indicated by red arrows in Figs. $2 b$ and $2 c$. To see how it was generated, the same fields as those shown in Fig. 6f, but over a (larger) domain similar to that of Fig. 2, are given in Fig. 9, showing the development of another LLEJ through the gap between Mt. Baerluke in the north and Mt. Alatau in the south that coincides with the distribution of the southern dust plume. Despite its stronger intensity than the northern LLEJ, no airborne sand/dust could be seen from satellite upstream from the plume-starting location because of the southern LLEJs passing over Lakes Alakol and Sasykkol, whose surfaces were covered with ice and snow on 11 March (Fig. 2a) but water on 12 and 13 March (Figs. 2b,c). Extreme $V_{\mathrm{SFC}}$ of over $35 \mathrm{~m} \mathrm{~s}^{-1}$ could be seen over the lake surfaces where frictional dissipation is markedly reduced. Moreover, $T_{\mathrm{SFC}}$ over the southern TCB was about $10^{\circ} \mathrm{C}$ warmer than that over the northern TCB, due to the presence of less cold air intrusion and more solar radiation received. So, the intense $V_{\mathrm{SFC}}$ could account alone for the generation of airborne sand and dust over an elongated zone along the southern LLEJ. Like the dust plumes shown in Figs. $2 b$ and $2 c$, this LLEJ diverges from the northern LLEJ after exiting the blocking regions of the mountain ranges (Fig. 9a). Clearly, the model captures the lateral and longitudinal extents of the two LLEJs, as verified by the two satellite-detected dust plumes (cf. Figs. 9a and 2c). 
Although the abovementioned processes were operative at all sand/dust-generating sites over the eastern TCB, surface observations at TC and YM and the other sites showed different timings in the occurrence of the severe dust storm. Specifically, as indicated by Fig. 3, TC and YM experienced intense $V_{\mathrm{SFC}}$ near 1200 and 1400 LST 11 March, respectively, but did not report airborne dust until 0305 and 0920 LST 12 March, respectively. The lagged onset timings (i.e., 15 vs $19 \mathrm{~h}$ ) between the severe wind and dust storms and the difference in the timing (i.e., about $6 \mathrm{~h}$ ) of dust generation/arrival at the two stations appear to reflect different processes leading to their $T_{\mathrm{SFC}}$ and $V_{\mathrm{SFC}}$ : namely, more (much less) Chinook influences at YM (TC), different depths of snow cover for melting/sublimation, and different soil moisture contents for drying near YM and EM. Subsequently, the sand/dust-raising winds at the strongest Chinook site (i.e., in YM's east-southeast) (cf. Figs. $6 f$ and $2 b$ ), blew up sand and dust into a deep layer, likely up to $3.5 \mathrm{~km}$ MSL, at which altitude intense turbulent mixing (i.e., as represented by large $K_{m}$ ) reaches (see Fig. 7), which was then transported west-northwestward by the LLEJ. The dust trace is so significant that it can be used to verify the model-simulated wind field over the TCB. Much less sand and dust were generated at 1138 LST 13 March, as the downslope winds started weakening (Figs. 2c, 3). By 1556 LST 13 March, no airborne sand and dust were reported at the source regions.

Finally, the horizontal distribution of isobars at $800 \mathrm{~m}$ MSL is given in Fig. 9b in order to gain insight into the pressure-driven dynamics in the generation of the LLEJ and its long-range dust transport in the present case. That is, the incoming cold air is accelerated from the higher-pressure upwind side to the lower-pressure TCB as it moves across the constricting saddle pass. The incoming airflow is peaked at the exit region (e.g., LFK), where its cold air mass rapidly spreads out laterally, like gap winds, plus the subsequent downslope motion, leading to lowering depths of the associated cold columns (as indicated by downward-tilted isentropic surfaces in Figs. 7a,b) and lowering pressures; this is similar at point $\mathrm{T}$ at the northwestern exit region over the western slope of Mt. Bahatai (Fig. 9b). On average, the $800-\mathrm{m}$ pressures decrease from the eastern portion of the TCB, where a deep layer of cold air is blocked by the mountain mass to the east, north, and south, to the northwestern portion along the LLEJ: for example, from $940 \mathrm{hPa}$ at the exit of the saddle pass to $930 \mathrm{hPa}$ at the northwestern exit of Mt. Bahatai over a distance of about $400 \mathrm{~km}$. Thus, the LLEJs (and associated dust plumes) are mostly driven by near-zonal pressure gradient forces, except in the vicinity of Mt. Alatau and Mt. Bahatai, where the cold flows are forced to move along their lateral surfaces, even with some winds pointing to higher pressures. Evidently, the intensity and vertical structures of the LLEJs do not appear to fit the geostrophic and thermal wind relationships. It follows that the far westward extension of the LLEJs can be attributed to the decreasing pressures toward the TCB's far west, as can also be seen from Figs. 4d-f. As discussed in section $2 \mathrm{~b}$, the relatively warmer air, advected into the TCB prior to the dust storm event, facilitates the penetration of the cold air mass into the far west.

A close-up examination of Fig. 9b shows an increase from a low pressure center of less than $938 \mathrm{hPa}$ near LFK to a high pressure center of more than $940 \mathrm{hPa}$ (denoted by "H") at $30-40 \mathrm{~km}$ downstream, which is hydrostatically associated with the downward-tilted followed by upward-tilted isentropic surfaces, causing deceleration followed by acceleration of the LLEJ (cf. Figs. $9 \mathrm{~b}$ and $7 \mathrm{~b}, \mathrm{~d})$. The intensity changes of the LLEJ occur not only at $800 \mathrm{~m}$ MSL (Figs. 6e and 9b), but also at the surface (Fig. 6f). Similarly, the topographical influences of blocking and downslope acceleration could account for the subsequent fluctuations of the LLEJ, passing across a mountain barrier of over $500 \mathrm{~m}$ to the west of China's border (Figs. 9b and 6e,f). However, the LLEJ at the surface weakens rapidly with distance after moving out of the mountain-blocking regions, due mainly to the rapid lateral spreading of the cold air mass and secondarily to frictional dissipation. All of these reveal the various roles of complex topography in determining the magnitude and spatial variation of the LLEJ.

\section{Summary and conclusions}

In this study, we examined the development of the 12-13 March 2006 wind/dust storm over the TCB of northwest China, which is surrounded by complex topography. This wind/dust storm, whose main dust source region was previously covered by snow with frozen soil, involves the superimposition of several orographically forced flows (i.e., saddle pass, downslope winds, and mountain blocking) in the presence of a large-scale, cold, easterly flow in the lower troposphere. Observational analyses indicate that the large-scale easterly flow was geostrophically maintained by a quasi-stationary high and low pressure system to the northeast and southeast of the TCB, respectively, and accompanied by a westward-moving cold front with an intense inversion layer near the altitudes of the mountain ridges. A high-resolution model simulation shows the generation of an LLEJ of near-typhoon strength, peaking at $500 \mathrm{~m} \mathrm{AGL}$ as the large-scale easterly flow moves through a constricting saddle pass and then undergoes a 
downslope motion. The LLEJ is then merged with an airstream from downslope winds as the large-scale easterly flow moves across a high mountain ridge to the southwest of the saddle pass, followed by a shortwave lower parallel ridge. The development of the downslope winds across the major ridge in the presence of a basic-state critical level near $700 \mathrm{hPa}$ fits well with the two-layer hydraulic jump model, that is, changing from subcritical on the upwind side to supercritical after passing the ridge crest, especially on 12 March. The existence of the lower ridge helps enhance the intensity of the downslope winds. The merged LLEJ is then forced to move along a near-zonally oriented mountain range in the north. Given the frozen soil with snow coverage, the intense downslope winds and associated surface warming appear to be essential to the melting and drying of the soil land near the foot of steep mountains and then for raising dust into a deep layer up to $3.5 \mathrm{~km}$ MSL before the LLEJ can transport the airborne dust into the TCB's far west.

While the downslope winds play an important role in generating the major dust storm, we have shown the formation of another intense LLEJ through a gap between Mt. Baerluke and Mt. Alatau that coincides with the distribution of a southern dust plume. This dust plume is driven completely by this southern LLEJ with little influences of downslope winds because of the land surface having above $0^{\circ} \mathrm{C}$ temperatures over the southern TCB. Although some errors in the simulated $T_{\mathrm{SFC}}$ and $V_{\mathrm{SFC}}$ are present at the northern and southern edges of the LLEJ, we may state that the WRF Model captures reasonably well the lateral and longitudinal extents of both LLEJs, as verified against the satellite-detected dust plumes, and their general intensities, as verified by available surface observations. This is not surprising, given the dominant roles of the large-scale easterly flow and well-resolved topographical morphologies. Thus, this work provides hope to predict the development of such intense wind/dust storms over the region and an example to study the impact of various topographical configurations on airflows for the problems of air quality, wind energy, engineering (construction), and cloudfog formations using numerical models. Even in the presence of a weak, large-scale, easterly flow in which $F_{R}<1$ may occur at the major ridge crests, several saddle passes/gaps around the TCB could serve as channels for the generation of LLEJs. In a forthcoming manuscript, we will examine the sensitivity of the simulated LLEJs to various topographical morphologies mentioned in this study.

Acknowledgments. We thank three anonymous reviewers and editor D. Kirshbaum for their helpful comments, Dr. Wei Wang of the National Center for
Atmospheric Research for her programming assistance, and Ms. Hua Liu of the China Meteorological Administration Training Centre for her earlier English editorial assistance. Ms. Zhimin Feng of the Xinjiang Meteorological Bureau provided the Terra/MODIS data for Fig. 2, and this study was supported by the National Natural Science Foundation of China Grants 41375070 and 41075050 and the Project of the Xinjiang Meteorological Bureau: Application of the Atmospheric Component Observations in the CAPPS3 Model. DLZ was also funded by the National Basic Research Program of China (973 Program) under Grant 2014 CB441402 and ONR Grant N000141410143.

\section{REFERENCES}

Belušić, D., M. Hrastinski, Z. Večenaj, and B. Grisogono, 2013: Wind regimes associated with a mountain gap at the northeastern Adriatic coast. J. Appl. Meteor. Climatol., 52, 20892105, https://doi.org/10.1175/JAMC-D-12-0306.1.

Bougeault, P., and Coauthors, 1993: The atmospheric momentum budget over a major mountain range: First results of the PYREX field program. Ann. Geophys., 11, 395-418.

- , and Coauthors, 2001: The MAP special observing period. Bull. Amer. Meteor. Soc., 82, 433-462, https://doi.org/10.1175/ 1520-0477(2001)082<0433:TMSOP>2.3.CO;2.

Brinkmann, W. A. R., 1974: Strong downslope winds at Boulder, Colorado. Mon. Wea. Rev., 102, 592-602, https://doi.org/ 10.1175/1520-0493(1974)102<0592:SDWABC>2.0.CO;2.

Cameron, D. C., 1931: Easterly gales in the Columbia River gorge during the winter of 1930-1931-Some of their causes and effects. Mon. Wea. Rev., 59, 411-413, https://doi.org/10.1175/ 1520-0493(1931)59<411:EGITCR >2.0.CO;2.

Clark, T. L., and W. R. Peltier, 1984: Critical level reflection and the resonant growth on nonlinear mountain waves. J. Atmos. Sci., $\mathbf{4 1}$, 3122-3134, https://doi.org/10.1175/1520-0469(1984)041<3122: CLRATR $>2.0 . \mathrm{CO} ; 2$.

Colle, B. A., and C. F. Mass, 2000: High-resolution observations and numerical simulations of easterly gap flow through the Strait of Juan de Fuca on 9-10 December 1995. Mon. Wea. Rev., 128, 2398-2422, https://doi.org/10.1175/1520-0493(2000)128<2398: HROANS $>2.0 . \mathrm{CO} ; 2$.

Colman, B. R., and C. F. Dierking, 1992: The Taku wind of southeast Alaska: Its identification and prediction. Wea. Forecasting, 7, 49-64, https://doi.org/10.1175/1520-0434(1992)007<0049: TTWOSA $>2.0 . \mathrm{CO} ; 2$.

Dudhia, J., 1989: Numerical study of convection observed during the Winter Monsoon Experiment using a mesoscale twodimensional model. J. Atmos. Sci., 46, 3077-3107, https://doi.org/ 10.1175/1520-0469(1989)046<3077:NSOCOD>2.0.CO;2.

Durran, D. R., 1986: Another look at downslope windstorms. Part I: The development of analogs to supercritical flow in an infinitely deep, continuously stratified fluid. J. Atmos. Sci., 43, 2527-2543, https://doi.org/10.1175/1520-0469(1986)043<2527: ALADWP $>2.0 . \mathrm{CO} ; 2$.

_ 1990: Mountain waves and downslope winds. Atmospheric Processes over Complex Terrain, Meteor. Monogr., No. 23, Amer. Meteor. Soc., 59-81.

- 2003: Downslope winds. Encyclopedia of the Atmospheric Sciences, J. Holton, J. Curry, and J. Pyle, Eds., Academic Press, 644-650. 
Gohm, A., G. J. Mayr, A. Fix, and A. Giez, 2008: On the onset of bora and the formation of rotors and jumps near a mountain gap. Quart. J. Roy. Meteor. Soc., 134, 21-46, https://doi.org/ 10.1002/qj.206.

Grubišić, V., and Coauthors, 2008: The Terrain-Induced Rotor Experiment: A field campaign overview including observational highlights. Bull. Amer. Meteor. Soc., 89, 1513-1534, https://doi.org/10.1175/2008BAMS2487.1.

Hong, S. Y., and J. O. Lim, 2006: The WRF single-moment 6-class microphysics scheme (WSM6). J. Korean Meteor. Soc., 42, 129-151.

_, Y. Noh, and J. Dudhia, 2006: A new vertical diffusion package with an explicit treatment of entrainment processes. Mon. Wea. Rev., 134, 2318-2341, https://doi.org/10.1175/MWR3199.1.

Jackson, P. L., and D. G. Steyn, 1994: Gap winds in a fjord. Part I: Observations and numerical simulation. Mon. Wea. Rev., 122, 2645-2665, https://doi.org/10.1175/1520-0493(1994)122<2645: GWIAFP $>2.0 . \mathrm{CO} ; 2$.

Jiang, Q., and J. D. Doyle, 2004: Gravity wave breaking over the central Alps: Role of complex terrain. J. Atmos. Sci., 61, 2249-2266, https://doi.org/10.1175/1520-0469(2004)061<2249: GWBOTC $>2.0 . \mathrm{CO} ; 2$.

Kain, J. S., 2004: The Kain-Fritsch convective parameterization: An update. J. Appl. Meteor., 43, 170-181, https://doi.org/ 10.1175/1520-0450(2004)043<0170:TKCPAU>2.0.CO;2.

Klemp, J. B., and D. K. Lilly, 1978: Numerical simulation of hydrostatic mountain waves. J. Atmos. Sci., 35, 78-107, https://doi.org/ 10.1175/1520-0469(1978)035<0078:NSOHMW > 2.0.CO;2.

Lackmann, G. M., and J. E. Overland, 1989: Atmospheric structure and momentum balance during a gap-wind event in Shelikof Strait, Alaska. Mon. Wea. Rev., 117, 1817-1833, https://doi.org/ 10.1175/1520-0493(1989)117<1817:ASAMBD>2.0.CO;2.

Lehner, M., and Coauthors, 2016: The METCRAX II field experiment: A study of downslope windstorm-type flows in Arizona's Meteor Crater. Bull. Amer. Meteor. Soc., 97, 217-235, https:// doi.org/10.1175/BAMS-D-14-00238.1.

Lilly, D. K., 1978: A severe downslope windstorm and aircraft turbulence event induced by a mountain wave. J. Atmos. Sci., 35, 59-77, https://doi.org/10.1175/1520-0469(1978)035<0059: ASDWAA $>2.0 . \mathrm{CO} ; 2$.

_ linear hydrostatic mountain waves. J. Fluid Mech., 95, 241261, https://doi.org/10.1017/S0022112079001452.

Lin, Y.-L., 2007: Mesoscale Dynamics. Cambridge University Press, $630 \mathrm{pp}$.

Liu, M., D. L. Westphal, A. L. Walker, T. R. Holt, K. A. Richardson, and S. D. Miller, 2007: COAMPS real-time dust storm forecasting during Operation Iraqi Freedom. Wea. Forecasting, 22, 192-206, https://doi.org/10.1175/WAF971.1.

Long, R. R., 1954: Some aspects of the flow of stratified fluids: II. Experiments with a two-fluid system. Tellus, 6A, 97-115, https://doi.org/10.1111/j.2153-3490.1954.tb01100.x.

Mlawer, E. J., S. J. Taubman, P. D. Brown, M. J. Iacono, and S. A. Clough, 1997: Radiative transfer for inhomogeneous atmospheres: RRTM, a validated correlated-k model for the longwave. J. Geophys. Res., 102, 16663-16 682, https://doi.org/ 10.1029/97JD00237.

Mobbs, S. D., and Coauthors, 2005: Observations of downslope winds and rotors in the Falkland Islands. Quart. J. Roy. Meteor. Soc., 131, 329-351, https://doi.org/10.1256/qj.04.51.

Reed, T. R., 1931: Gap winds of the Strait of Juan de Fuca. Mon. Wea. Rev., 59, 373-376, https://doi.org/10.1175/1520-0493(1931)59<373: GWOTSO $>2.0 . \mathrm{CO} ; 2$.

Sharp, J., and C. F. Mass, 2004: Columbia Gorge gap winds: Their climatological influence and synoptic evolution. Wea. Forecasting, 19, 970-992, https://doi.org/10.1175/826.1.

Skamarock, W. C., and Coauthors, 2008: A description of the Advanced Research WRF version 3. NCAR Tech. Note NCAR/ TN-475+STR, 113 pp, https://doi.org/10.5065/D68S4MVH.

Smith, C. M., and E. D. Skyllingstad, 2011: Effects of inversion height and surface heat flux on downslope windstorms. Mon. Wea. Rev., 139, 3750-3764, https://doi.org/10.1175/2011MWR3619.1.

Smith, R. B., 1977: The steepening of hydrostatic mountain waves. J. Atmos. Sci., 34, 1634-1654, https://doi.org/10.1175/15200469(1977)034<1634:TSOHMW>2.0.CO;2.

— 1985: On severe downslope winds. J. Atmos. Sci., 42, 25972603, https://doi.org/10.1175/1520-0469(1985)042<2597: OSDW $>2.0 . \mathrm{CO} ; 2$.

Steenburgh, W. J., D. M. Schultz, and B. A. Colle, 1998: The structure and evolution of gap outflow over the Gulf of Tehuantepec, Mexico. Mon. Wea. Rev., 126, 2673-2691, https:// doi.org/10.1175/1520-0493(1998)126<2673:TSAEOG >2.0.CO;2.

Vosper, S. B., 2004: Inversion effects on mountain lee waves. Quart. J. Roy. Meteor. Soc., 130, 1723-1748, https://doi.org/10.1256/qj.03.63.

Whiteman, C. D., 2000: Mountain Meteorology: Fundamentals and Applications. Oxford University Press, 355 pp.

Zhang, D., and R. A. Anthes, 1982: A high-resolution model of the planetary boundary layer-Sensitivity tests and comparisons with SESAME-79 data. J. Appl. Meteor., 21, 1594-1609, https:// doi.org/10.1175/1520-0450(1982)021<1594:AHRMOT>2.0.CO;2.

Zhu, H., and H. S. Zhang, 2010: An estimation of the threshold friction velocities over the three different dust storm source areas in northwest China (in Chinese). Acta Meteor. Sin., 68, 977-984. 